\title{
Linguistic exhaustivity inference is context dependent
}

\author{
A visual-world eye-tracking study \\ on Hungarian focus
}

\author{
Tamás Káldi \\ Research Institute for Linguistics, \\ Hungarian Academy of Sciences \\ kaldi.tamas@nytud.mta.hu
}

\section{Anna Babarczy}

Budapest University of Technology and Economics babarczy@cogsci.bme.hu

\begin{abstract}
The study investigates contextual effects on the processing of pre-verbal (preVf) and postverbal (postVf) focus sentences in an eye-tracking experiment. For comparison, lexically marked focus (only-f) sentences were also included. The test sentences were presented following two types of linguistic context: restrictive or non-restrictive. It was hypothesized that if preVf exhaustivity is purely structurally encoded, gaze will converge on the exhaustive target image at a similar rate in the two contexts, just as it does in the case of only-f. However, if context also has an effect on the emergence of exhaustivity in preVf, gaze should converge more slowly on the exhaustive target in the non-restrictive context than in the restrictive context as predicted in postVf. The results support the latter prediction: fixation patterns diverge in the case of both preVf and postVf sentences, while they do not in the case of the baseline only-f.
\end{abstract}

Keywords: Hungarian focus; exhaustive inference; scalar implicature; experimental pragmatics; eye-tracking

\section{Introduction}

According to the Constraint-based model of implicature processing, contextual factors strongly determine both the likelihood of implicature generation and the time course of mental processes associated with it (see e.g., Degen \& Tanenhaus 2015). Conversely, the Modular model (or Literal first model) predicts an always present delay relative to semantic processing regardless of contextual factors (see e.g., Huang \& Snedeker 2009). ${ }^{1}$

${ }^{1}$ For an introduction to the differences between the two types of processing models also see Foppolo \& Marelli (2017). 
Since the exhaustivity inference associated with Hungarian structural foci has experimentally been shown to be associated with pragmatic implicature, these sentence types are especially suitable for testing the processing related predictions of the above mentioned models. Thus, the present study investigates the interpretational characteristics of contextually embedded Hungarian focus containing sentences in a series of three visual world eye-tracking experiments. The sentence types investigated are (i) lexically marked focus (only-f), (ii) pre-verbal focus (preVf) and (iii) post-verbal focus (postVf). The experiments seek to answer the question whether contextual restriction on the available alternatives has an effect on the exhaustive interpretation of these sentence types and on the time course of the identification of the focused element's referent. The identification of such an effect - or the lack of it - could serve the purpose of adjudicating on the debate regarding the models of implicature processing.

Another reason for testing Hungarian focus sentences with regard to these questions lies in the novelty of the question and method itself: to our knowledge, no work has addressed the potential effects of context on the interpretation of Hungarian focus constructions using online, processing related measurements.

The outline of the paper is as follows. First, we provide a brief introduction to the theory of scalar implicature and the psycholinguistic models of implicature processing. Second, a short outline of the theoretical and experimental findings on Hungarian focus is given. We also elucidate the implicature status of the exhaustive inference associated with Hungarian foci. Fourth, the experiments are presented, and finally, we make our concluding remarks.

\subsection{Psycholinguistic models of scalar implicature processing}

Before turning our attention to the models of scalar implicatures, a short explanation of the theory of scalars is due.

\subsubsection{Scalar implicatures: theory}

According to Gricean theory (see e.g., Grice 1957; 1975; 1989; Horn 1972; Gazdar 1979), there are expressions whose interpretation is associated with so called scalar implicatures. For example such an interpretation is found in (1b) derived from (1a) through Grice's (1975) maxims.

(1) a. Some (of the) guests went home. b. Some but not all of the guests went home.

c. Some and possibly all of the guests went home. 
Since (1c) entails (1a) (i.e., in all worlds where (1c) is true (1a) must also be true), the quantifier expressions in them (all and some) form a scale: some $<$ many $<$ most < all (Horn 1972; Gazdar 1979). According to the theory, the pragmatically enriched or implicated meaning of some corresponds to $(5 \mathrm{~b})$, i.e., an upper-bounded interpretation, while the interpretation corresponding to (1c) is a lower-bounded interpretation.

According to Grice's formulation, the implicature is generated through the Maxim of Quantity: if we assume that the interlocutors are cooperative, their contribution will be optimally informative. For this reason, if in the given case it was true that all of the guests went home, then the speaker would not opt for using the less informative alternative in (1a). Therefore, the fact the (s)he did use the sentence in (1a) implies (1b) in terms of the Maxim of Quantity. Relevance Theory (Sperber \& Wilson 1995) uses a similar reasoning: the greatest cognitive effect achieved in the speaker if by hearing (1a) (s)he generates the interpretation corresponding to (1b).

\subsubsection{Scalar implicatures: models of processing}

As mentioned in the introductory paragraph, there are two prominent competing psycholinguistic models of scalar implicature generation: the Modular or Literal-first model and the Constraint-based model. ${ }^{2}$ We will start our discussion by describing the Modular model. In loose terms the Modular model is inspired by the Gricean reasoning outlined in the previous section to the extent that the labor of generating a scalar implicature is divided between semantics and pragmatics in two consecutive steps: the truth-conditional meaning of the scalar-containing expression has to be calculated before the pragmatically enriched interpretation is reached. The cognitive effort made after the calculation of the semantic meaning is measurable in the elongated time course of scalar activation relative to those interpretations associated with purely semantic processing. Such differences have been reported in an extensive array of experimental work (see e.g., Noveck \& Posada 2003; Bott \& Noveck 2004; De Neys \& Schaeken 2007; Tomlinson et al. 2013; Huang \& Snedeker 2009). Authors reporting these results advocate the Modular model.

Since the methodology and results of Huang \& Snedeker (2009) are especially relevant to our study, we will briefly describe these here. The authors tested the Modular model by using the visual-world paradigm comparing the interpretational processes related to some, a scalar term,

${ }^{2}$ Levinson's (2000) Default model is not relevant for our purposes, therefore it will not be mentioned in the present paper. 
all, a term whose interpretation is purely semantic, and two numerals as controls (two and three). During the experimental trials participants heard instructions containing one of these quantifiers (e.g., Point to the girl who has two/three/all/some of the socks) and were presented four image quadrants. The target images depicted the lower-bounded (semantic) reading in the all-condition, an exact reading in the number-conditions, and the upper-bounded (pragmatically enriched) reading in the some-condition. The experimental task was to carry out the instruction. Based on the Modular model, the authors expected that eye-tracking data would show a slower convergence on the target image for the pragmatically interpretable some-instructions than for the semantically interpretable number- and allinstructions. The results showed the expected latency differences: participants' looks converged on the target image in the some-condition relatively later during the period between quantifier onset and the end of the sentence than in the all-condition. According to Huang \& Snedeker (2009), the observation that interpretational processes related to semantically interpretable expressions were faster than those related to pragmatic ones shows that the Modular model is suitable for capturing the differences between semantic and pragmatic interpretation as carried out by the mind.

The Modular model has been criticized both on theoretical and empirical grounds. To our mind, one of the most important theoretical criticisms was formulated by Geurts and Rubio-Fernández (2015). The authors develop their main point using Marr's (1982) three levels of analysis: they claim that Grice's theory never intended to answer questions related to 'how'; it is a theory of 'what' and 'why'. In other words "Grice never meant to advance a processing theory" (Geurts \& Rubio-Fernández 2015, 446): the steps of pragmatic reasoning are not necessarily carried out in the mind as Grice and his followers made it explicit in the formulation of their theory. One simplified example of such reasoning was outlined in section 1.1.1. Since Geurts and Rubio-Fernández (2015) question the psychological reality of the semantics - pragmatics divide as formulated in the Gricean theory, they also point out the untenability of the Modular model of linguistic interpretation, or of the "two-system models" in their terminology (ibid., 465). Such systems are attractive, since the process of generating interpretations can be divided into routinely or automatically run processes (i.e., semantic processing in the Modular model) and into those that require more attention and effort (i.e., pragmatic processing). As the authors' reasoning goes, the system would have to be able to decide whether to opt for a pragmatically enriched interpretation or not. In order to achieve this, an intermediary module is needed which constantly 
monitors the output of the semantic module and makes evaluations about whether processing should be continued by the pragmatic module based on context, world knowledge, etc. However, for the system to work, the intermediary module should be at the level of sophistication of the pragmatic module. Consequently, as Geurts and Rubio-Fernández $(2015,465)$ put it, "the whole point of a two-system architecture is lost". The criticism of two-system models ultimately boils down to the difficulties of how the two components should interact with each other. Clearly, Geurts and RubioFernández (2015) take a strong view against strictly relating the theoretical concepts of the semantics - pragmatics division to actual mental processes of implicature derivation.

A prominent competing alternative to the Modular model is the Constraint-based model which claims that contextual factors have an effect on the rate and time course of implicature generation. The model therefore predicts that under certain circumstances, the latency differences observed by Huang and Snedeker (2009) and a number of other authors advocating the Modular model can disappear. A wide array of experimental work has been inspired by this hypothesis(see e.g., Grodner et al. 2010; Degen \& Tanenhaus 2011; Bergen \& Grodner 2012; Breheny et al. 2013; Degen \& Tanenhaus 2015; Foppolo \& Marelli 2017).

For the sake of exposition, in what follows we provide a non-exhaustive list of the contextual factors that have been found to have an effect on the rate and/or time course of implicature generation. These factors include the knowledge-state of interlocutors (Bergen \& Grodner 2012), the linguistic form expressing the upper-bounded meaning and also the felicity of its use in the given context (Grodner et al. 2010; Degen \& Tanenhaus 2011), the experimental task (Káldi et al. 2017), or the number of elements that certain quantifiers associated with scalar implicature operate on (subitizing range) (Degen \& Tanenhaus 2010). Although the studies listed here differed, sometimes substantially, in their methodology, a common finding is that contextual factors can eliminate the rate and time course differences between the activation of "purely" semantically interpreted meanings and those tied to scalar inferences.

In the body of research mentioned above, there is an experimental finding that bears direct relevance for our purposes: Káldi et al. (2017) examined the time course of preVf interpretation in two visual world eyetracking experiments in which they found that the experimental task has a critical effect on both the rate and the time course of generating exhaustive interpretation associated with the structure at hand. The study will be discussed in more detail in section 1.2.3. 


\subsection{Hungarian foci}

Typologically, Hungarian is a discourse configurational language. In discourse configurational languages information structural functions such as Topic or Focus are "expressed through a particular structural relation" (É. Kiss 1995, 6). In the forthcoming sections we will briefly outline the structural relations pertaining to preVf and postVf. Also, theoretical and empirical findings on the interpretational characteristics of these structures will be discussed.

\subsubsection{The word order properties of Hungarian pre-verbal- and post-verbal focus sentences}

The experiments in the present paper investigate two variants of the object - focus sentence: preVf and postVf presented in (2a) and (2b) respectively.

(2) a. Andris [egy'almát] rakott rá a tányérjára.

Andrew an apple-ACC put-3SG-PST onto $(=\mathrm{VM})$ the plate.his.onto

'Andrew put an 'apple onto his plate.'

b. Andris rárakott [egy'almát] a tányérjára.

Andrew onto-put-3SG-PST an apple-ACC the plate.his.onto

'Andrew put an apple onto his plate.'

The structural difference between preVf and postVf sentences examined in the present study lies primarily in their word order. Specifically, in the preVf sentence $(2 \mathrm{a})$, the focused NP is immediately pre-verbal and the verbal modifier (VM) is located post-verbally (É. Kiss 2002). PreVf also has an inherent prosodic feature: the focused element bears a so called eradicating stress, i.e., it is assigned a prominent sentential stress which "eradicates" all subsequent stresses in the remaining part of the focus containing clause (Kornai \& Kálmán 1988). On the other hand, in the postVf sentence $(2 \mathrm{~b})$, the (VM) occupies the immediately pre-verbal position and forms one phonological word with the verb, while the NP sits in a postverbal position. According to Surányi (2011), the post-verbally focused element is assigned a main stress, however, to our knowledge no phonetic measurement data is available on the prosodic characteristics of the postverbal element in sentences of type $(2 \mathrm{~b}) .^{3}$

${ }^{3}$ Genzel et al. (2015) measured the prosodic characteristics of post-verbal foci, however, these elements were different from those used in the present study in at least two respects. First, Genzel et al. (2015) used syntactically discontinuous backgrounds (i.e., the post-verbal focused element was both preceded and followed by syntactic units 


\subsubsection{The interpretational characteristics of pre-verbal focus: theoretical findings}

By now classical theoretical studies such as Szabolcsi (1980), É. Kiss (1998) or Kenesei (2006) have set the course for the investigation of the interpretational properties of preVf by laying the main emphasis on the exhaustive interpretation of the structure. By exhaustive interpretation we mean that the focused element refers to an entity in the universe of discourse for which the predicate of the sentence exclusively holds (see e.g., É. Kiss 1998). For example, in the case of (2a), the discourse universe can be a set of fruits ([apple, pear, peach]), of which the sentence uniquely identifies the apple as the entity for which it holds that Andrew put that entity onto his plate. This operation has the natural consequence that all remaining potential referents (i.e., the members in the set of fruits in the present example) are excluded from the set of entities for which the predicate of the preVf sentence holds. For this reason, as Kenesei $(2006,137)$ points out, preVf "identifies by exclusion": the entity identified through focus is identified with relation to a complementary set. Furthermore, he adds that "whether or not the contrasting complementary set is explicit, in the case of contrastive focus a complementary set is always created". 4

Consequently, the majority of analyses of preVf within the theoretical linguistic tradition concentrate on exhaustivity as an interpretational component. Within the generative tradition ${ }^{5}$ a broad array of work captures exhaustivity by positing an operator with a [+Exhaustive] feature in the representation of preVf structures (see e.g., Szabolcsi 1981; Farkas 1986; É. Kiss 1998; Kenesei 2005; 2006; É. Kiss 2002; 2008; Kenesei 2009; Horvath 2010). Although these accounts differ in details irrelevant to our purposes, they share an important common tenet: they claim that exhaustivity is coded grammatically and that it is part of the truth-conditional

corresponding to the information structurally backgrounded part of the sentence). On the other hand, our study used sentence-final focus phrases; a position least prominent in Hungarian. Second, the authors used quantified expressions as focus (e.g., két filmet - two films), whereas in the present study NPs with an indefinite article were used. For this reason, the otherwise compelling results reported in Genzel et al. (2015) are not directly applicable in the present study.

${ }^{4}$ Kenesei's analysis will be of special relevance concerning the interpretation of exhaustive response rates (see section 5.1).

${ }^{5}$ There are alternative accounts within the generative literature, like for example Szendrôi (2003). Although generative in nature, Szendrôi (2003) does not advocate the operator-driven approach, but remains noncommittal about the explanation of exhaustivity in the case of preVf. 
meaning of the preVf sentence. These accounts therefore can be subsumed under the term grammatical- or feature-driven approaches and predict a deterministic relationship between structure and exhaustive interpretation in the case of preVf.

One of the most frequently cited theoretical works criticizing the grammatical approach and propagating an alternative explanation for exhaustivity in the case of preVf is Wedgwood (2005). According to the author, exhaustivity can be accounted for in the framework of Relevance Theory (RT), and the postulation of an exhaustivity operator is unnecessary: if in a given discourse we mention the element or elements of an explicitly or implicitly given set, it follows from the principle of Relevance that the other members of this set will be excluded. PreVf is thus underspecified for exhaustive interpretation while exhaustiveness is the most informative interpretational alternative requiring the least cognitive effort. ${ }^{6}$ Furthermore, Wedgwood et al. $(2006,14)$ provide evidence for the implicature status of the exhaustivity by citing corpus data in which preVf co-occurs with an expression meaning 'among others' (3).

(3) [...] akiket útjukra többek között [Anna Lindh svéd külügyminiszter] kísér majd el. [...] they will also be accompanied by among others [the Swedish foreign minister Anna Lindh]

According to Wedgwood (2005) and Wedgwood et al. (2006), the example in (3) illustrates an instance of cancellation. Since cancellability is a definitive feature of pragmatic phenomena, the author concludes that the exhaustive interpretation of preVf has the status of an implicature. ${ }^{7}$

The above brief summary of the two opposing theoretical strands illustrates the fact that research has mostly concentrated on exhaustivity as an interpretational aspect, and its possible motivations. Since these conflicting accounts provided a basis for well-testable hypotheses, the theoretical debate has inspired a broad array of psycholinguistic experiments. The following section presents a brief overview of these.

\subsubsection{The interpretational characteristics of pre-verbal focus: experimental findings}

The theoretical approaches to the interpretation of preVf suggest that the structure at hand has an exhaustive reading. However, the results of a wide

${ }^{6}$ For details on what is meant by "cognitive effort" in the case of preVf and exhaustive interpretation see section 1.2.3.

${ }^{7}$ For a critical review of Wedgwood's analysis see É. Kiss (2006). 
array of experiments on the subject have unambiguously demonstrated that the exhaustive interpretation is not an entirely reliable tendency. For this reason, a number of authors claim that exhaustivity emerges through pragmatic inferences (see e.g., Onea \& Beaver 2011; Kas \& Ágnes Lukács 2013; Gerốcs et al. 2014; Káldi 2016; Káldi \& Babarczy 2016). Before turning our attention to these results, we present Pintér (2018), a work with a different stance. ${ }^{8}$

Pintér (2018) analyzes the exhaustive interpretation of preVf along the dimensions of at-issueness and claims that this meaning component has the status of a presupposition. The author believes that the analysis of the exhaustivity in preVf is controversial while acknowledging that "experimental studies carried out thus far (except for Skopeteas \& Fanselow $2011)^{9}$ seem to support the view that it is an implied and therefore strongly context-dependent content". Contrary to these findings, Pintér (2018) hypothesizes that exhaustivity in preVf is a not-at-issue presupposed content. In order to test this hypothesis, the author carried out an experiment on children (from the age of five to nine divided into three groups) and adult controls using a sentence-picture verification paradigm with a three-point Likert response scale. Participants heard a pre-recorded sentence and saw a picture in one of four conditions: (i) exhaustive-condition, (ii) false-condition, (iii) non-exhaustive-condition and (iv) exhaustive-withdistractor-condition. The task of the participants was to rate the test sentence in the context of the picture on the three-point scale consisting of smiley faces expressing three different emotions: (i) sad face: "unacceptable", (ii) neutral face: "not entirely good or bad either", (iii) happy face: "acceptable/good". Pintér's (2018) results revealed that for preVf sentences, the proportion of happy faces decreased with age in the non-exhaustive condition. These results show that the exhaustive reading of the given structure was more available to older participants. Although the results are interesting and are in line with earlier experimental findings, it is hard to see how Pintér's (2018) results support the view that exhaustivity in preVf sentences is presupposed as opposed to implied, as no independent evidence is provided to support this claim. ${ }^{10}$ Note that implicature violations

${ }^{8}$ We would like to thank the editor for drawing our attention to this work.

${ }^{9}$ Since, as Pintér $(2018,385)$ also points it out, the results of Skopeteas \& Fanselow (2011) are not directly comparable to the results of the majority of studies on the interpretational characteristics of preVf, that work is not discussed here.

10 The standard test for presupposition is that it survives under negation and questions, whereas for implicature it is cancellablility. An experiment designed along these lines may help us adjudicate between the two opposing views. 
(or pragmatic violations in a broader sense) tend to receive similar ratings (cf. Katsos \& Bishop 2011).

In an earlier study using essentially the same method, Babarczy and Balázs (2016) also found the interpretational trends in children (from the age of four to ten in three groups) reported by Pintér (2018). However, Babarczy and Balázs (2016) hypothesized that exhaustivity in the case of preVf emerges as a pragmatic (scalar) implicature and attempted to seek independent evidence by also assessing participants' cognitive control abilities through a battery of different standardized tests. The rationale behind correlating cognitive control and the rate of implicature generation is as follows. It has been shown in by now classic studies (cf. e.g., Noveck 2001; Bott \& Noveck 2004; Foppolo \& Guasti 2012) that implicature generation incurs extra cognitive effort (also see predictions of RT outlined in section 1.2.2.). If the exhaustive interpretation of preVf is tied to implicature generation, then children with lower cognitive control abilities should derive the exhaustive inference at a lower rate than those who score higher on tests measuring these abilities. Babarczy and Balázs's (2016) results showed that this is indeed the case. Although, as the authors also admit, this study is correlational, and therefore no causal relationship can be inferred regarding the strength of cognitive control abilities and the rate of exhaustive interpretation, these findings provide some independent evidence regarding the implicature status of the meaning component at hand.

Another important study, Gerốcs et al. (2014), carried out on adults directly manipulated the available cognitive resources allocated for the derivation of the exhaustive interpretation of preVf. The authors compared the interpretation of preVf sentences in a picture-sentence verification experiment: participants heard preVf or postVf sentences after which they saw images corresponding to exhaustive or non-exhaustive scenarios. The task of the participants was to decide if the images matched the previously heard sentence. The authors manipulated the time available for the response. Geroocs et al. (2014), predicted that the limitation of time and therefore of cognitive resources available for the process of interpretation will result in responses that reflect the semantic meaning of the presented sentences, whereas if more time is available (and thus pragmatic enrichment can take place), responses will reflect the pragmatic meaning. The results were in line with the authors' predictions: in the short-condition the rate of exhaustive responses in the case of preVf sentences was around chance level, while in the long-condition the rate of exhaustive responses was significantly higher $(72 \%)$ but still well below 100\%. Gerốcs et al. (2014) concluded that the exhaustive interpretation of 
preVf emerges as a pragmatic inference. In another experiment the authors compared the interpretational characteristics of lexically marked (only) focus (henceforth only-f), preVf and cleft sentences in a sentence - picture matching paradigm. Participants read a sentence of one of the aforementioned types and had to decide which of four images matched the sentence best. The number of images that could be chosen was not limited to one. The set of four images included one depicting an exhaustive interpretation, a non-exhaustive image and two distractors. The results revealed that participants gave an exhaustive response in $98 \%$ of the trials in the only-f-condition, while the rate of exhaustive responses was well below that in the cleft- and preVf-conditions ( $54 \%$ and $35 \%$ respectively). Gerócs et al. (2014) concluded that these results support the view that exhaustivity is not entailed but emerges as a result of a pragmatic inference.

Another important finding was reported by Káldi et al. (2017) already mentioned in section 1.1.2. The authors looked at the rate and time course of exhaustive interpretation of preVf sentences in a forced-choice and a multiple choice visual-world experiment, and found that task type had a profound effect: if the choice is limited to one, preVf is invariantly exhaustive, and the time course of referent identification is identical to that of lexically marked focus. Conversely, if there is no such restriction on the choice, the rate of non-exhaustive interpretation increases, and a greater competition between exhaustive and non-exhaustive targets is seen relative to only-f. As the authors' reasoning goes, if the experimental task is conceptualized as a context for the sentence stimuli, the differences in results between the forced-choice and the multiple-choice experiments also support the hypothesis that the exhaustive inference associated with preVf has the status of implicature. The forced-choice task employed in the first experiment introduced a contextual restriction regarding the potential referents of the focused elements. Since this restriction suggests that the number of the potential referents is one, the processing system does not consider potential alternatives. However, if there is no such restriction, the number of potential alternatives increases and the processing effort associated with the identification of the unique referent increases as well. After all, if preVf is semantically underspecified for exhaustive interpretation, the computation of this interpretational component should require more effort than that associated with the lexically and semantically unambiguous only-f sentences. The experiments by Káldi et al. (2017) thus raise an interesting question regarding the context dependence of the exhaustive interpretation of preVf and of the mental processes associated with this interpretation. However, as context dependence can only be inferred indirectly from the 
results of Káldi et al. (2017), the question is worth investigating using experiments specifically designed to measure interpretation with contextual factors as manipulated variables. One of the aims of the current research is to carry out a measurement in which the contextual factors potentially affecting focus interpretation are manipulated more directly by linguistic means.

There is another crucial aspect raised in Káldi et al. (2017) according to which the exhaustive interpretation of preVf emerges through scalartype implicature: the listener maximizes the information content (or cognitive effect) of the heard sentence by assuming that the predicated part of the sentence is not true for other entities except for the referent of the focused element. The reasoning is best illustrated through the sentences in (1) analogous to those in (5). Examples in (1) are repeated in (4) for convenience. While the semantic meaning of (5a) is compatible with (5c), just as (4a) is compatible with (4c), the most informative interpretational alternative for $(5 a)$ is $(5 b)$, as (4b) is with relation to (4a).

(4) a. Some (of the) guests went home.

b. Some but not all of the guests went home.

c. All of the guests went home.

(5) a. Juli ment haza. (preVf) 'It was Juliet who went home.'

b. Julin kívül más nem ment haza. 'No one went home except for Juliet.'

c. Juli és mások is hazamentek. 'Juliet went home along with others.'

In this respect the exhaustive interpretation of preVf is an upper-bounded interpretation.

The authors of the present paper believe that through a direct manipulation of the linguistic context the hypothesis related to the scalar implicature status of exhaustivity in preVf can be tested more directly.

\subsubsection{The interpretational characteristics of post-verbal focus: theoretical findings}

Less attention has been devoted to postVf and its interpretational characteristics both in the theoretical and in the experimental domains. Perhaps the most prominent definitive and principled distinction was first made by É. Kiss (1998). First of all, É. Kiss $(1998,246)$ claims that contrary to 
preVf, postVf 11 "is not associated with movement", or it "has no designated structural position in the sentence" (ibid., 260), and second, that postVf carries non-presupposed information. However, no claim is formulated with respect to its interpretational characteristics. It is Surányi (2011) who provides a detailed analysis of the interpretation of postVf with special emphasis on its potential exhaustivity and the status of the interpretational component at hand.

According to the author, the emergence of exhaustive interpretation in the case of postVf hinges on the type of explicit or implicit question that it intends to answer. There are two types of potential questions that have a definitive role: "Mention some!" and "Mention one!" type of questions. Both question types can be felicitously answered by a postVf sentence. The former question type requires an answer which refers to a subset of the potentially available alternatives. Exhaustivity is not part of the truthconditions of such an answer. However, a postVf sentence can potentially be an answer to a "Mention all!" type of question in which case the postVf sentence - following the question - designates all the elements for which the proposition of that sentence holds. Surányi (2011) thus concludes that since the exhaustive interpretation of postVf sentences depends on the type of (potentially implicit) question which they are an answer to, and therefore exhaustivity is context dependent, this meaning component is a pragmatic one.

\subsubsection{The interpretational characteristics of post-verbal focus: experimental findings}

As far as experimental evidence is concerned, Gerôcs et al. (2014) also provide interesting data. They compared the interpretation patterns of not only preVf but also postVf sentences. Using the method of limiting the time available for the processing of a sentence (outlined in detail in section 1.2.3) they found that when no such limitation is introduced, the rate of exhaustive interpretation for preVf and postVf sentences is $73 \%$ and $63 \%$ respectively, however when a time limit is imposed, these rates fall to $53 \%$ and $41 \%$. The authors explain the results regarding postVf sentences in a similar vein as those related to preVf. In order to calculate a pragmatically enriched meaning, extra cognitive resources are needed. If the availability of these resources is limited (for example due to a limited amount of time for them to operate), the pragmatically enriched meaning is not computed. It is also important from our perspective that Gerôcs

11 "Information focus" in É. Kiss's terminology. 
et al. (2014) did not find a statistically significant difference between the rates of exhaustive interpretation in the two sentence type conditions. The authors reason that this similarity of interpretation patterns is "expected, assuming that exhaustivity is caused by the same pragmatic mechanisms in both sentences with pre-verbal focus and sentences with the noun phrase in a post-verbal position" (ibid., 188).

In their experimental work, Tóth and Csatár (2017) also hypothesized that the exhaustive interpretation associated with postVf sentences is derived through implicature. To examine this hypothesis, the authors ran an acceptability rating study and manipulated contextual variables arguing that if exhaustivity in these two sentence types is pragmatically determined, different contextual factors will have an effect on the emergence of this meaning component. The linguistic stimuli consisted of short question - answer pairs in which the answer was either an object focus preVf sentence or a corresponding postVf sentence. An example of these pairs is given in (6).

(6) a. Mit fogott ki Bence?

'What did Ben catch?'

b. Bence egy halat fogott ki. (preVf - expected) 'It was a fish that Ben caught.'

c. Bence kifogott egy halat. (postVf - expected) 'Ben caught a fish.'

d. Bence egy nyakláncot fogott ki. (preVf - unexpected) 'It was a necklace that Ben "caught".'

e. Bence kifogott egy nyakláncot. (postVf - unexpected) 'Ben "caught" a necklace.'

Four context conditions were used in the experiment: expected object (6b) and (6c), unexpected object (6d) and (6e), exhaustive context and nonexhaustive context. The latter two contexts were instantiated through images depicting different scenarios. In exhaustive contexts the image depicted an exhaustive scenario (e.g., boy catching one fish), or a nonexhaustive one (e.g., boy catching two fish). Tóth and Csatár (2017) predicted that (i) the contextual factors will have an effect on the acceptability rates of both sentence types, (ii) there will be no difference between the acceptability rates of the two sentence types within the different context conditions. The results partially supported the first prediction: while both sentence types were accepted in exhaustive contexts, the acceptability rate fell to chance level in non-exhaustive contexts. The factor of predictability, however, had no effect: participants accepted both sentence types as 
correct at the same rate in both the expected, and the non-expected conditions. The second prediction was entirely supported by the results: the acceptability ratings were not different for preVf and postVf sentences within any of the context conditions. Tóth and Csatár (2017, 242) emphasize that their "most important finding [...] is the fact that exhaustivity had the same effect on both preVf and postVf sentences. Therefore, experimental evidence has been provided in favor of Surányi's (2011) claim about the exhaustivity of postVf sentences".

\subsection{Overview, goals}

In order to establish the rationale for the experiments in the current paper, a summary of the most important points is given here.

A question we address concerns the modular versus constraint-based approach to implicature processing. With respect to the time course of processing, the model predicts that there should be a delay for scalar terms relative to expressions whose interpretation can be calculated purely at the level of semantics. For eye-tracking data this would mean a delay of looks to a target which corresponds to the pragmatically enriched interpretation of the given scalar term. A Constraint-based model does not predict such a delay, since it claims that contextual factors are taken into consideration throughout the process of interpretation, and pragmatically enriched meaning is calculated immediately if context supports it. The current study will contribute further data to this debate by examining the potential effects of the linguistic contextual factors on the exhaustive interpretation of preVf and postVf sentences. If the Constraint-based model is correct, looks to the exhaustive target should converge earlier during the interpretation of a focus construction in a context that supports an exhaustive interpretation than in a context that does not directly support exhaustivity. If the Modular-model is correct, no such difference is expected. The preVf and postVf sentence types are suitable for testing psycholinguistic models of implicature generation, since experimental work has shown that exhaustivity arises as a pragmatic implicature in both preVf and postVf.

We shall also investigate the effects of linguistic contextual restriction on the rate and time course of exhaustive interpretation in the structures at hand to gather further evidence on the status of their exhaustive interpretation. If the exhaustive interpretation is indeed a pragmatic inference for preVf as well as for post $\mathrm{ff}$ but not for lexically marked exhaustiveness (i.e., only-phrases), we expect sentential context to affect the interpretation of the former two but not of the latter. As far as the context dependence of 
exhaustivity is concerned, so far only indirect evidence has been provided regarding preVf (Káldi et al. 2017) and, to the best of our knowledge, no experimental work using online methodology has addressed the issue with regards to postVf.

In the forthcoming sections we report the method and results of our experiments. Experiments 1 and 2 investigate the relevant properties of preVf, Experiment 3 concentrates on postVf sentences.

\section{Experiment 1}

\subsection{Participants}

32 native Hungarian adults with normal or corrected to normal vision participated in the experiment. Since three of the participants had to be excluded due to technical reasons, data from 29 individuals (17 female, 12 male, mean age 22.9 years, $\mathrm{SD}=6.7$ ) were analyzed.

\subsection{Materials}

The experiments presented in the current paper were carried out with an EyeLink 1000 eye-tracker by SR Research at a $500 \mathrm{~Hz}$ sampling rate. The experiments were programmed in the Experiment Builder software.

An example of the test linguistic stimulus of one trial is given in Table 1. Each trial consisted of a four-sentence story. Independently of the condition, the first sentence introduced the scene and the second (set) sentence explicitly designated a set of entities (e.g., fruits, such as apple, pear, and peach). The third (context) sentence either restricted the number of elements about which the final sentence made a statement, or it did not introduce such a restriction. These will be referred to as restrictive and non-restrictive conditions respectively. The final word of the context sentence was egyet (one-ACC) in the restrictive-condition, and néhányat (some-ACC) in the non-restrictive-condition. In order to make all combinations of context and test sentences felicitous and the stories coherent, the context sentences were created in deontic modality. The fourth (test) sentence was either a preVf sentence, or a lexically marked focus (only-f) sentence functioning as a control condition. The use of only-f sentences as a control condition was justified on the grounds that exhaustivity in these sentences is lexically marked, and occurs context-independently. The focused element in the test sentence always corresponded to one of 
the elements explicitly mentioned in the set in the first sentence. The element which the focused word corresponded to was randomized: it corresponded to the first, second and third element of the set sentence in an equal proportion of the trials. The purpose of this balanced randomization was to control for participant expectations about which element from the set will be referred to by the test sentence. All test sentences contained a sentence-final adverbial phrase as demonstrated in the examples of Table 1.

Table 1: Example stimuli for Experiment 1

\begin{tabular}{|c|c|c|c|}
\hline $\begin{array}{l}\text { Number } \\
\text { of sentence }\end{array}$ & $\begin{array}{l}\text { Function } \\
\text { of sentence }\end{array}$ & $\begin{array}{l}\text { Type } \\
\text { of sentence }\end{array}$ & Example \\
\hline 1 & set & - & $\begin{array}{l}\text { Az asztalon volt egy tál tele gyümölcsökkel. Volt } \\
\text { ott sok alma, körte, barack. 'There was a bowl full } \\
\text { of fruit on the table. There were a lot of apples, } \\
\text { pears, peaches.' }\end{array}$ \\
\hline \multirow{2}{*}{2} & \multirow{2}{*}{ context } & restrictive & $\begin{array}{l}\text { Minden vendég vehetett a tányérjára egyet. 'Every } \\
\text { guest could put ONE fruit onto their plate.' }\end{array}$ \\
\hline & & non-restr. & $\begin{array}{l}\text { Minden vendég vehetett a tányérjára néhányat. } \\
\text { 'Every guest could put SOME fruits onto their } \\
\text { plate.' }\end{array}$ \\
\hline \multirow{2}{*}{2} & \multirow{2}{*}{ test } & only-f & $\begin{array}{l}\text { János csak egy almát rakott rá a tányérjára. 'John } \\
\text { only put an apple onto his plate.' }\end{array}$ \\
\hline & & preVf & $\begin{array}{l}\text { János egy 'almát rakott rá a tányérjára. 'John put } \\
\text { an 'apple onto his plate.' }\end{array}$ \\
\hline
\end{tabular}

The use of two context types (restrictive and non-restrictive) and two test sentence types (preVf and only-f) resulted in four conditions: (i) restrictive context and only-f, (ii) non- restrictive context and only-f (iii) restrictive context and preVf, (iv) non-restrictive context and preVf. The experiment contained 24 test trials ( 6 of each condition) and 48 filler trials. To ensure that each participant was presented all the trials, and that each condition could be presented in an equal proportion, four counterbalanced lists were created. Participants were assigned to the lists in random order.

The linguistic stimuli were recorded in a sound treated room with an external sound card and an omnidirectional microphone (digitized at $44.1 \mathrm{kHz}$ sampling rate and at 16 bit resolution). The stimuli were prerecorded by a native adult female Hungarian speaker and were presented through speakers during the experiment. As it was pointed out in section 
1.2.1, preVf is characterized by a so called eradicating stress. Accordingly, during the recording of the linguistic material, we asked our speaker to use a natural prosody for the test sentences, and use this stress pattern in a way that it forms a naturally sounding continuation for the preceding part of the linguistic stimulus. As an illustration of the f0, contours corresponding to the relevant prosodic aspects of the test sentences, a prototypical example for both sentence types is shown in Figures 1 and 2. Figures of $\mathrm{fo}$ contours in the present paper were created using Praat software (Boersma \& Weenink 2017).

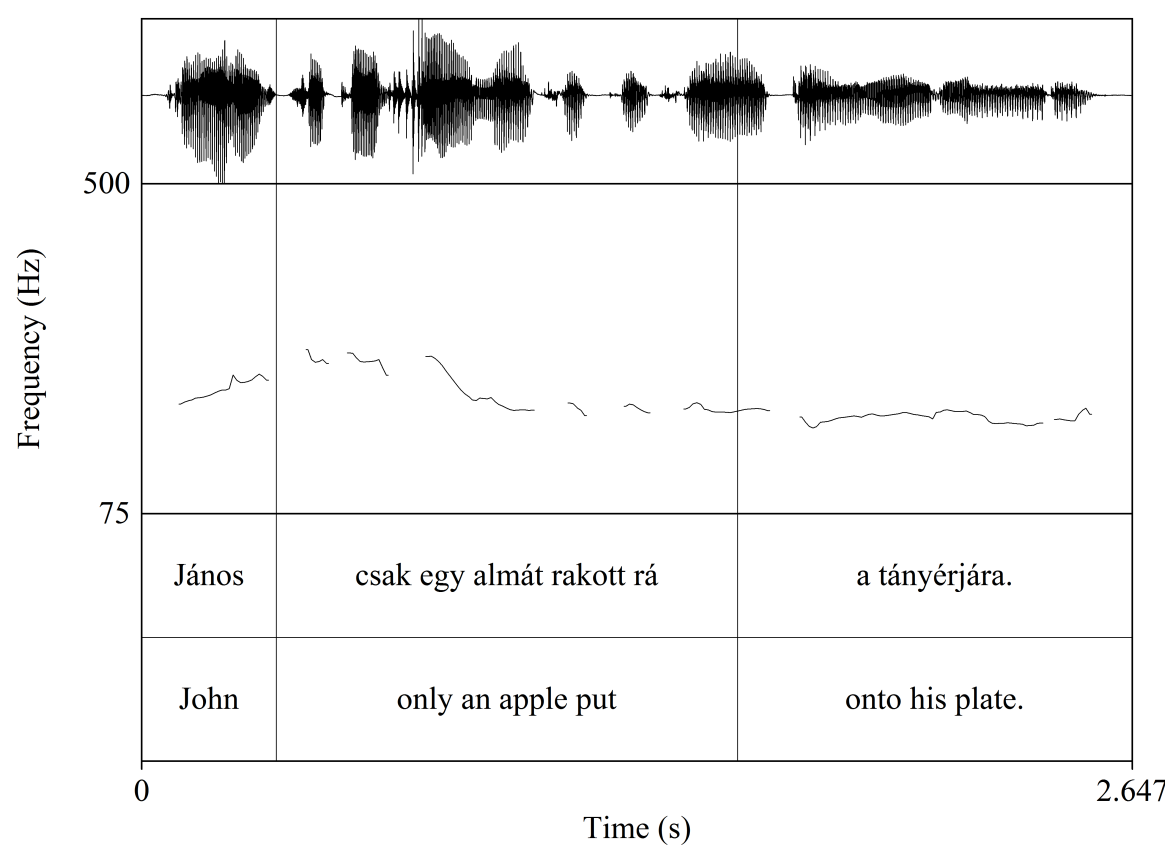

Figure 1: The f0 contour of a prototypical only-f sentence used in the experiment

The visual stimuli were presented in color on a screen in four image quadrants (Figure 3). One of the four quadrants depicted the exhaustive target, and one depicted a non-exhaustive alternative. The other two images served as distractors.

The position of image types in the four quadrants and the relative positions of images within the quadrants were balanced and randomized. In order to reduce the strain on participants' eyes, we set the background of the whole experiment to grey (RGB: 210, 210, 210). 


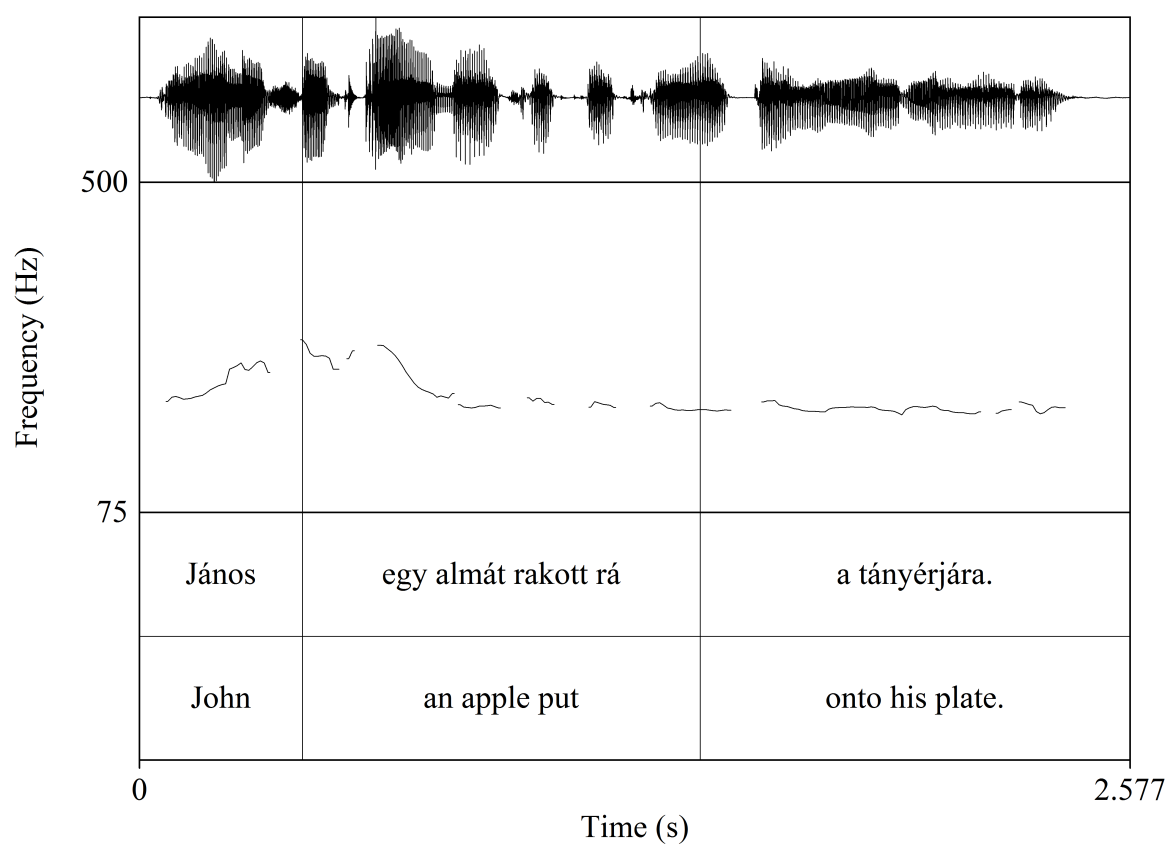

Figure 2: The f0 contour of a prototypical preVf sentence used in the experiment
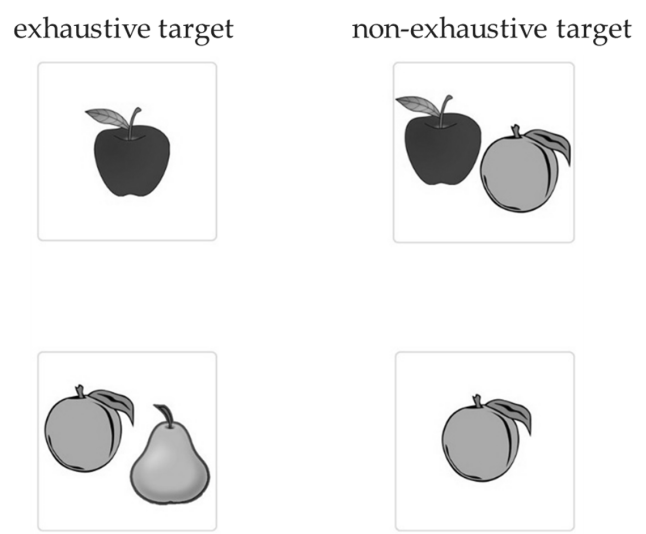

non-exhaustive distractor

exhaustive distractor

Figure 3: An example of the visual stimuli (corresponding to the linguistic material presented in Table 1). Labels were not seen by the participants, they were added for illustration. 


\subsection{Procedure}

The procedure within each trial went as follows (Figure 4). The participant looked at an empty grey screen while listening to the first three (introductory, set and context) sentences. After the presentation of the sentences a fixation circle occurred. The experiment was programmed in a way that the trial continued only if the participant looked at this circle. This way the measurement of eye-tracking data started with the participants' gaze being at the centre of the screen at an equal distance from each quadrant. When the participant looked at the circle, it disappeared and the four quadrants (Figure 3) were presented simultaneously with the third (test) sentence. The task of the participant was to select the quadrant or quadrants that best corresponded to the test sentence using a button box (RESPONSEPixx Handheld). After selecting the quadrant or quadrants the participant pressed the middle button and a new trial started after a 2000 ms delay.

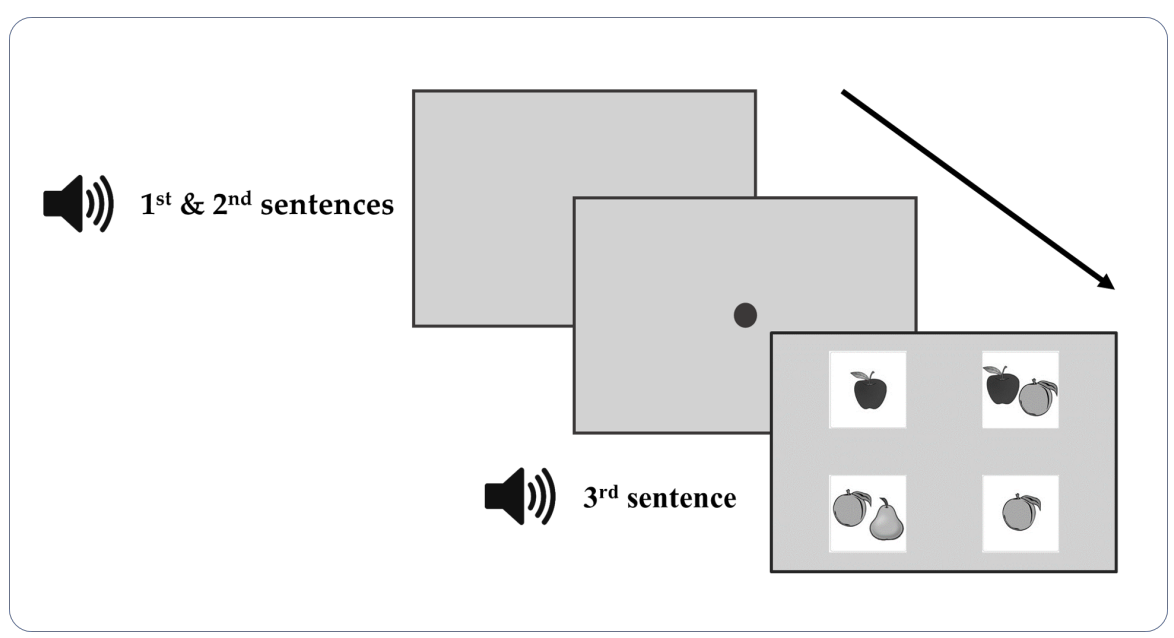

Figure 4: Trial sequence

The order of test and filler trials were randomized in a way that there were no two consecutive test trials. The fillers included trials in which the number of image quadrants corresponding to the last sentence was either one, two or three. The number of these different filler types was balanced. This arrangement encouraged participants to entertain more than one possible alternative while selecting the images. 
The experiment consisted of two blocks of trials: a practice block and a test block. The first block contained five practice trials after which participants were given feedback on their performance. If a participant performed the task incorrectly, the given trial was repeated. The practice trials were similar to the filler trials of the test block. The primary aim of the first block was to help participants practice the use of the button box, and to accommodate to the experimental situation. During the practice block, and immediately after it, participants could adjust the volume of the speakers to a convenient level. At the beginning of the practice block the experimenter emphasized that although by giving feedback during the practice block we suggest that there are correct and incorrect answers throughout the experiment, this is actually not the case: in the test block there are no 'correct' and 'incorrect' responses; the experiment tests participants' intuitions, and feedback was included only for practical purposes. Correspondingly, no feedback was given during the test block.

Two dependent variables were analyzed: (i) the rate of exhaustive image choices, and (ii) the number of fixations on the exhaustive target as a function of time in the trials where an exhaustive response was given. Regarding these variables we predicted the following. Based on Káldi et al. (2017), we expected that the choice of images would be uniformly exhaustive in the only-f-condition in both restrictive and non-restrictive contexts. However, in the preVf-condition we predicted a divergence: in the case of restrictive contexts we still expected a relative dominance of exhaustive image choices, whereas in non-restrictive contexts we expected a drop in the frequency of exhaustive responses and a rise in the likelihood of nonexhaustive responses.

Regarding the eye-tracking data, predictions were made only for those trials in which participants gave an exhaustive response, since a direct comparison is possible only in these cases. In the only-f-condition we expected that eye-gaze would converge on the exhaustive target image independently of the context condition. In contrast, we expected a divergence between the two context conditions in the preVf sentence condition. Also based on Káldi et al. (2017), it was predicted that while in the restrictive context eye-gaze would reliably converge on the exhaustive target image, in the non-restrictive contexts this convergence would be less reliable showing that participants are also taking the non-exhaustive alternative image into consideration. Since the referent of the focused element is disambiguated only after the end of the verb phrase, we expected this divergence to occur during the sentence-final adverbial phrase (AdvP). 


\subsection{Results}

\subsubsection{Rate of exhaustive responses}

The data on the choice of images (i.e., the rate of exhaustive interpretation) entirely supported our predictions, as shown in Figure 5. A response was categorized as exhaustive if only the exhaustive target image was selected. A response was categorized as non-exhaustive if only the non-exhaustive or both the non-exhaustive and the exhaustive target images were selected.

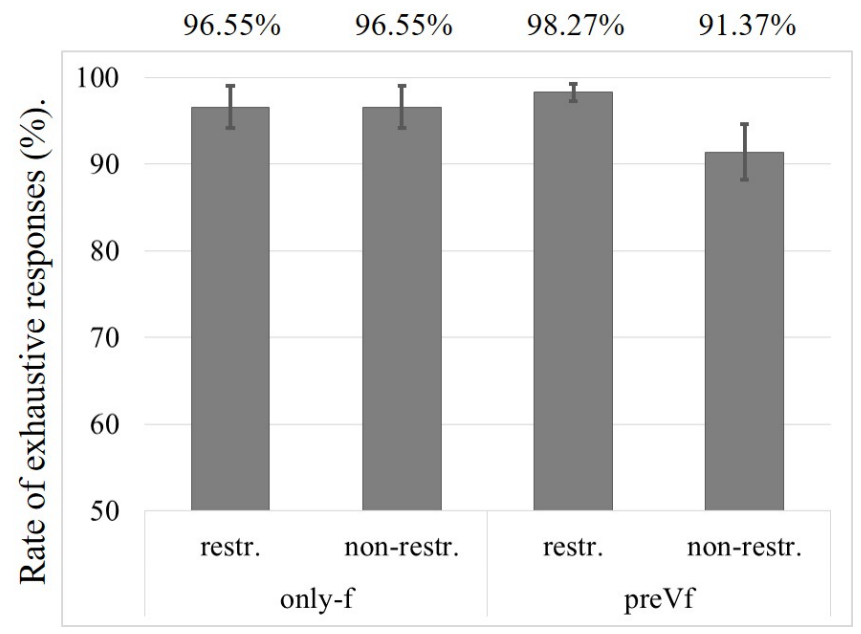

Figure 5: Rate of exhaustive response type in the four conditions. The $y$ axis starts at $50 \%$ for expository purposes.

For statistical analysis, a series of binomial Logistic Mixed Effects Models were fitted with Participant and Item as random factors and Context and Sentence Type as fixed factors. ${ }^{12}$ The outcome variable was the participants' response, which could be exhaustive (0) or non-exhaustive (1) as defined above. Model building started with a full random structure and, if the model failed to converge, the structure was gradually simplified. This procedure resulted in models with random intercepts for Participant and Item. The fixed effects structure was built bottom up starting with an intercept-only model, to which the two fixed effects and their interaction were added one by one. Since the interaction model significantly improved model fit $\left(\chi^{2}(2)=13.33, p=.001\right)$, two separate models were built for the

12 Statistical analyses were carried out using the lme4 package (Bates et al. 2015) of the $R$ statistical software (R Core Team 2017). 
Table 2: Regression coefficients of the effect of a Restrictive Context on a NonExhaustive response

Response $\sim$ Context $+(1 \mid$ Participant $)+(1 \mid$ Item $)$, family $=$ binomial

\begin{tabular}{ccccc}
\hline & Estimate & SE & $z$ & $p$ \\
\hline Only-f Sentence Type & -0.00 & 5.26 & 0.00 & 1.00 \\
PreVf Sentence Type & -2.47 & 1.07 & -2.30 & .021 \\
\hline
\end{tabular}

two sentence types to obtain simple effect coefficients. In these models the only predictor was Context. The results are shown in Table 2, the coefficients show the effect of Restrictive context compared to Non-Restrictive context on the likelihood of giving a Non-Exhaustive response. As we can see, Context had no effect on Response in the only-f sentence condition but it did have an effect in the preVf sentence condition in the predicted direction: people were slightly but significantly less likely to give a nonexhaustive response in a restrictive context.

\subsubsection{Eye-tracking data}

The data were analyzed using mixed-effects logistic regression models with Participant and Item as random factors (Barr 2008; Jaeger 2008). The models used a Poisson distribution and predicted the number of fixations per $100 \mathrm{~ms}$ on the Exhaustive Target image over Time from the offset of the subject NP in the test sentence to the end of the test sentence shifted by $200 \mathrm{~ms}$ to allow for the planning and execution of eye movements (Allopenna et al. 1998). The models were built starting with an intercept-only model and gradually adding the fixed effects and their interactions. The models were compared using the likelihood ratio test and complexity was increased until the addition of a new term no longer improved model fit. In the final, best-fitting model Context and Sentence Type and their interaction were included as fixed effects on a third-order orthogonal polynomial capturing Time. A third-order polynomial was selected because it was a significantly better fit than either a linear model or a second-order polynomial as described by Mirman (2017). A full random effects model with random slopes for the various conditions failed to converge and was therefore removed from the analyses leaving a random intercept model for Participant and Item.

Where interaction terms were significant, separate mixed models were built to assess the simple slopes of the fixed factors while keeping all other model parameters constant. 
Figures 6 and 7 show the mean proportion of fixations on the Exhaustive Target Image relative to the competitor every 100 milliseconds in the Restrictive and Non-Restrictive Context conditions for only-f sentences and preVf sentences. Selected model parameter estimates with main effects and overall interactions are displayed in Table 3.

Table 3: Regression coefficients of the model predicting eye movements

ExhTarg (ot $1+$ ot $2+$ ot 3$) *$ Context $*$ Sentence

$+(1 \mid$ Participant $)+(1 \mid$ Item $)$, family $=$ poisson

\begin{tabular}{lrrrc}
\hline & Estimate & SE & $z$ & $p$ \\
\hline Intercept & 2.95 & 0.07 & 44.13 & $<.001$ \\
Time & 13.55 & 0.43 & 31.71 & $<.001$ \\
Time $^{\wedge} 2$ & 32.90 & 0.047 & 69.30 & $<.001$ \\
$\mathrm{Time}^{\wedge} 3$ & -8.17 & 0.41 & -19.79 & $<.001$ \\
Context Restrictive $_{\text {Sentence Type PreVf }}$ & 0.05 & 0.00 & 12.07 & $<.001$ \\
Context Restrictive: & 0.10 & 0.00 & 26.43 & $<.001$ \\
Sentence Type PreVf & 0.14 & 0.01 & 18.52 & $<.001$ \\
\hline
\end{tabular}

Sentence type: only-f

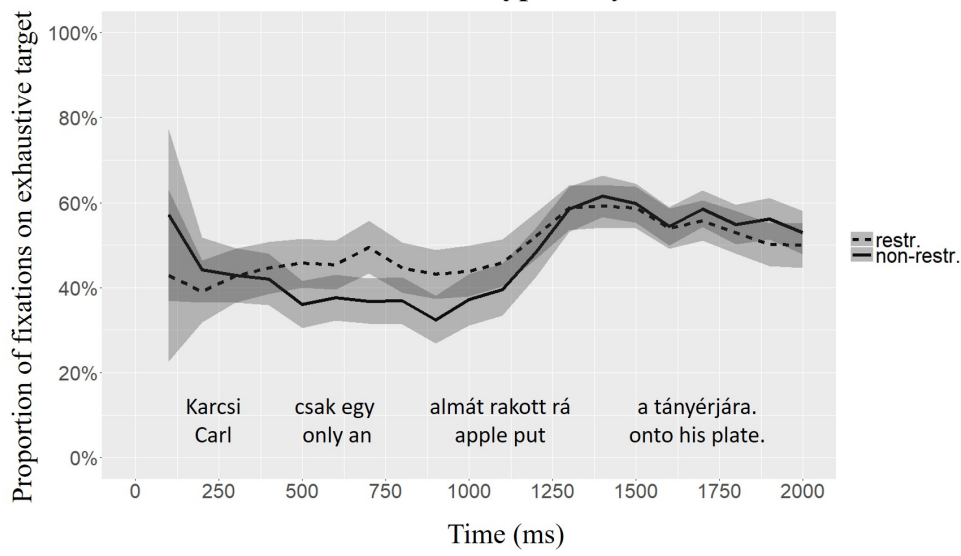

Figure 6: Mean proportion of fixations on the exhaustive target (fixations of exhaustive target / (fixations on exhaustive target + fixations on competitor)) in the only-f-condition (ribbons: 1SE). (Figures on eye-tracking data were created using the ggplot2 package for $R$ (Wickham 2009).) 


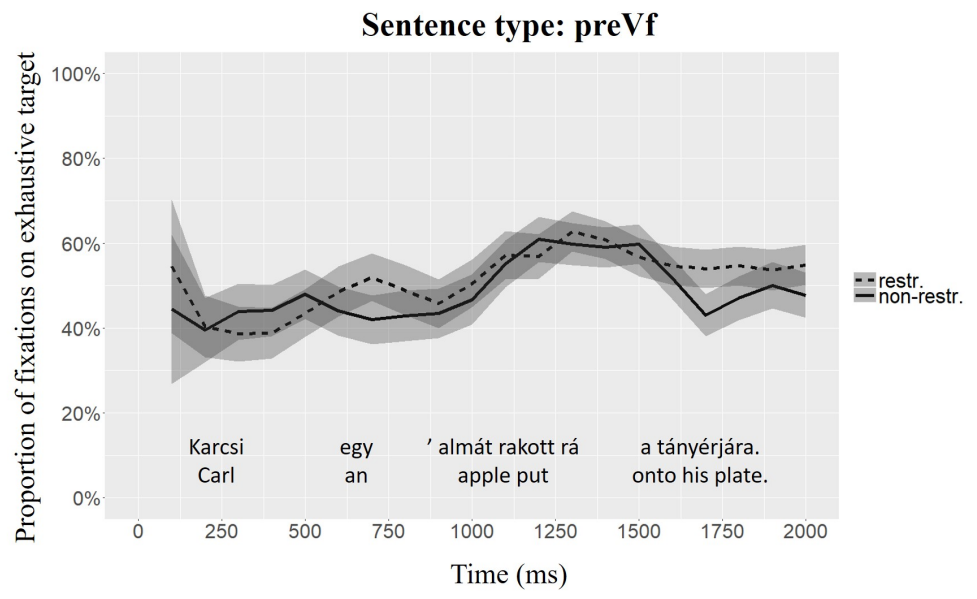

Figure 7: Mean proportion of fixations on the exhaustive target (fixations of exhaustive target / (fixations on exhaustive target + fixations on competitor)) in the preVf-condition (ribbons: 1SE)

The model shows an overall third-order polynomial trend in the data with the frequency of fixations on the exhaustive target slightly decreasing while the object NP is heard and then sharply increasing during the verb before falling again at the end of the sentence. Looks to the Exhaustive target were somewhat more frequent in the preVf sentence condition than in the only sentence condition. Context also had a slight but significant main effect: participants looked more at the exhaustive target in the Restrictive context condition than in the Non-Restrictive context condition. Most importantly, as expected, there was a significant Context by Sentence Type interaction. Two separate models for the two Sentence Types revealed that Context had a weak but significant effect on the number of fixations on the Exhaustive Target in the only-f sentence condition and this effect appeared in a surprising direction: participants were slightly less likely to fixate on the exhaustive target in the restrictive context condition than in the non-restrictive context condition $\left(\chi^{2}=44.35, p<.001, b=\right.$ $-0.04, z=-6.66, p<.001)$. As predicted, however, a restrictive context significantly increased the number of fixations on the exhaustive target relative to a non-restrictive context in the preVf sentence condition $\left(\chi^{2}=542.46, p<.001, b=0.13, z=23.27, p<.001\right)$. This effect was strongest on the quadratic time term $(b=10.50, z=26.42, p<.001)$.

Although the results of Experiment 1 are in line with our predictions and appear to demonstrate the effects of linguistically introduced restric- 
tion on the interpretation of preVf, there could be other explanations for the results because nothing in the experiment required participants to take context into consideration. That is, we cannot be certain that participants actually processed the context sentences.

For this reason, a new experiment was designed with some crucial modifications. First, context sentences were given a more prominent role by making trials more compact and by introducing new filler trials with or without quantifiers. These filler trials were designed such that their contexts and/or quantifiers had to be processed and integrated into the representation of the situation in order to be able to perform the experimental task correctly. This was done to ensure that participants would pay attention to the context sentences in every trial. Second, a short informal survey following Experiment 1 revealed that in our sentences of deontic modality the Hungarian translation of the quantifier some sounded unnatural. The survey's results further suggested that a better alternative for some would be the expression as many as they wished, which was judged to be compatible with both a set of one and a set of more than one, and therefore may be a more natural context for both the exhaustive and nonexhaustive readings of the following test sentences. The materials were therefore modified accordingly as described below in more detail.

\section{Experiment 2}

\subsection{Participants}

36 native Hungarian adults with normal or corrected to normal vision participated in the experiment. Twelve participants were excluded because they did not pass the threshold of $75 \%$ accuracy in filler trials leaving data from 24 individuals ( 21 female, 3 male, mean age 22.6 years, $S D=1.3$ ) for further analyses.

\subsection{Materials and procedure}

To focus attention on context, we reduced the number of sentences presented in each trial to two: a context sentence and a test sentence. The introductory sentence introducing the scene and the set sentence of Experiment 1 were omitted. The context sentence was modified to include a category name as shown in Table 4 . The quantifier in the non-restrictive context sentences was replaced: instead of some the expression as many as 
they wanted/could etc. was used. An example of a restructured test trial is presented in Table 4.

Table 4: Example stimuli for Experiment 2

\begin{tabular}{llll}
\hline $\begin{array}{l}\text { Number } \\
\text { of sentence }\end{array}$ & $\begin{array}{l}\text { Function } \\
\text { of sentence }\end{array}$ & $\begin{array}{l}\text { Type } \\
\text { of sentence }\end{array}$ & Example \\
\hline & restrictive & $\begin{array}{l}\text { Minden vendég vehetett a gyümölcsök közül egyet. } \\
\text { 'Every guest could put ONE of the fruits onto their } \\
\text { plates.' }\end{array}$ \\
\cline { 3 - 4 } 2 & context & non-restr. & $\begin{array}{l}\text { Minden vendég annyi gyümölcsöt vehetett a } \\
\text { tányérjára, amennyit csak akart. 'Every guest } \\
\text { could put AS MANY fruits onto their plates AS } \\
\text { THEY WANTED.' }\end{array}$ \\
\hline \multirow{2}{*}{1} & test & János csak egy almát rakott rá a tányérjára. 'John \\
& only put an apple onto his plate.' \\
\cline { 3 - 4 } & preVf & $\begin{array}{l}\text { János egy'almát rakott rá a tányérjára. 'John put } \\
\text { an 'apple onto his plate.' }\end{array}$ \\
\hline
\end{tabular}

For reasons mentioned in section 2.3, new fillers were created with three attributes. The first attribute was context-dependence: in context dependent filler trials the information coded in the context sentence was crucial; without relying on it, participants could not select the correct images. The second attribute was the presence of a quantifier, the processing of which was essential for the successful completion of the trial. In contextdependent quantified fillers the quantifier was included in the context sentence. In context-independent quantified trials the quantifier was part of the test sentence. These two attributes thus yielded four different combinations. An example filler trial for each combination is presented in Table 5.

In order to avoid learning effects, the number of fillers with each attribute combination was approximately equally balanced. Table 6 shows the distribution of attributes across filler trials.

The third filler attribute, also present in Experiment 1, was the number of image quadrants that were congruent with the linguistic stimulus. This number ranged from one to three.

The experiment consisted of 20 test trials and 40 filler trials and took approximately 30 minutes to complete. Apart from the modifications outlined above, the procedure of the experiment and all other aspects remained constant. 
Table 5: Types of fillers used in Experiment 2

\begin{tabular}{|c|c|c|}
\hline Feature & Func. of sent. & Example \\
\hline \multirow{2}{*}{$\begin{array}{l}\text { cont.-indep., } \\
\text { no quant. }\end{array}$} & context & $\begin{array}{l}\text { A telep múvészei szerepeltek a fotókiállításon. 'The } \\
\text { artists of the artists' colony presented their work at } \\
\text { the photo-exhibition.' }\end{array}$ \\
\hline & test & $\begin{array}{l}\text { Bence képein darvak voltak láthatók. 'Ben's photos } \\
\text { depicted cranes.' }\end{array}$ \\
\hline \multirow{2}{*}{$\begin{array}{l}\text { cont.-dep., } \\
\text { no quant. }\end{array}$} & context & $\begin{array}{l}\text { A fenyőfa ága rálógott a vezetékekre, ezért a lakók } \\
\text { úgy vélték, hogy le kell vágni. 'A branch of the pine } \\
\text { tree reached the electric cable, so the dwellers de- } \\
\text { cided to cut the branch.' }\end{array}$ \\
\hline & test & $\begin{array}{l}\text { Dénes meg is találta a megfelelố szerszámot. 'Dénes } \\
\text { found the appropriate tool.' }\end{array}$ \\
\hline \multirow{2}{*}{$\begin{array}{l}\text { cont.-indep., } \\
\text { quant. }\end{array}$} & context & $\begin{array}{l}\text { A költöztetók azt ígérték, hogy annyi teherautót } \\
\text { küldenek, amennyit csak tudnak. 'The movers } \\
\text { promised that they would send as many trucks as } \\
\text { they could.' }\end{array}$ \\
\hline & test & $\begin{array}{l}\text { Bár nem küldtek túl sokat, de legalább több, mint } \\
\text { egyet küldtek. 'Although they did not send many, } \\
\text { at least they sent more than one.' }\end{array}$ \\
\hline \multirow{2}{*}{$\begin{array}{l}\text { cont.-dep., } \\
\text { quant. }\end{array}$} & context & $\begin{array}{l}\text { Anna remélte, hogy a bőröndök közül már legalább } \\
\text { egyet bepakolt a férje. 'Anna hoped that his hus- } \\
\text { band had packed at least one of the suitcases.' }\end{array}$ \\
\hline & test & $\begin{array}{l}\text { Amikor benézett a szobába, elégedett volt. 'When } \\
\text { she peeked into the room, she was satisfied.' }\end{array}$ \\
\hline
\end{tabular}

Table 6: The distribution of attributes in filler trials used in Experiment 2

\begin{tabular}{lcc}
\hline Feature & + & - \\
Presence of quantifier & 21 & 19 \\
Context-dependence & 22 & 18 \\
\hline
\end{tabular}

The linguistic stimuli of Experiment 2 were also recorded in a sound treated room with an external sound card and an omnidirectional microphone (digitized at $44.1 \mathrm{kHz}$ sampling rate and at 16 bit resolution) in the production of an adult Hungarian female. 


\subsection{Results}

\subsubsection{Rate of exhaustive responses}

The data on the choice of images (i.e., the rate of exhaustive interpretation) weakly supported our predictions as shown in Figure 8.

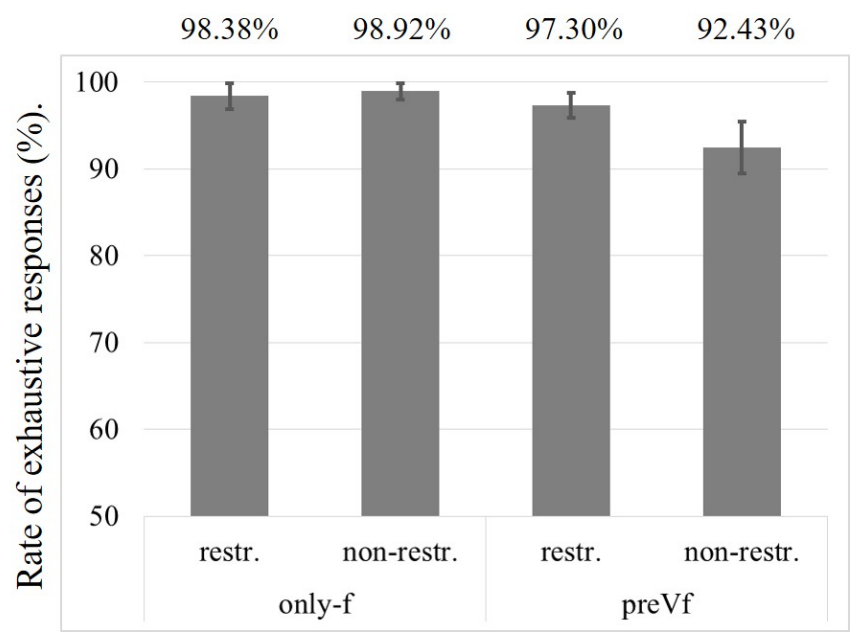

Figure 8: Rate of exhaustive response type in the four conditions

For statistical analysis, a series of binomial Logistic Mixed Effects Models were fitted with Participant and Item as random factors and Context and Sentence Type as fixed factors, as for Experiment 1. The outcome variable was the participants' response, which could be exhaustive (0) or non-exhaustive (1). Model building started with a full random structure and, if the model failed to converge, the structure was gradually simplified. This procedure resulted in models with random intercepts for Participant and Item. The fixed effects structure was built bottom up starting with an intercept-only model, to which the two fixed effects and their interaction were added one by one. Since the full model failed to converge, two separate models were built for the two sentence types to test the effects of Context. The results are shown in Table 7 . The coefficients show the effect of Restrictive context compared to Non-Restrictive context on the likelihood of giving a Non-Exhaustive response. As predicted, Context had no effect on Response in the only-f sentence condition $\left(\chi^{2}=1.38, p=0.28\right)$ but it did have an effect in the preVf sentence condition in the expected direction: 
people were slightly but significantly less likely to give a non-exhaustive response in a restrictive context $\left(\chi^{2}=3.57, p=.03\right.$, one-tailed $)$.

Table 7: Regression coefficients of the effect of a Restrictive Context on a NonExhaustive response

Response $\sim$ Context $+(1 \mid$ Participant $)+(1 \mid$ Item $)$, family $=$ binomial

\begin{tabular}{cccrc}
\hline & Estimate & SE & $z$ & $p$ \\
\hline Only-f Sentence Type & -0.03 & 0.00 & 0.00 & 1 \\
PreVf Sentence Type & -1.24 & 0.69 & -1.79 & .03 \\
\hline
\end{tabular}

\subsubsection{Eye-tracking data}

The data were analyzed using mixed-effects logistic regression models with Participant and Item as random factors (Barr 2008; Jaeger 2008). The models used a Poisson distribution and predicted the number of fixations per $100 \mathrm{~ms}$ on the Exhaustive Target image over Time from the offset of the subject NP in the test sentence to the end of the test sentence shifted by $200 \mathrm{~ms}$ to allow for the planning and execution of eye movements (Allopenna et al. 1998). The models were built starting with an intercept-only model and gradually adding the fixed effects and their interactions. The models were compared using the likelihood ratio test and complexity was increased until the addition of a new term no longer improved model fit. In the final, best-fitting model, Context and Sentence Type and their interaction were included as fixed effects on a third-order orthogonal polynomial capturing Time. A third-order polynomial was selected because it was a significantly better fit than either a linear model or a second-order polynomial as described by Mirman (2014). A full random effects model with random slopes for the various conditions failed to converge and was therefore removed from the analyses leaving a random intercept model for Participant and Item.

Where interaction terms were significant, separate mixed models were built to assess the simple slopes of the fixed factors while keeping all other model parameters constant.

Figures 9 and 10 show the mean frequency of fixations on the Exhaustive Target Image as a percentage of fixations on the target plus the competitor every 100 milliseconds in the Restrictive and Non-Restrictive Context conditions for only-f sentences and for preVf sentences. Selected 
model parameter estimates with main effects and overall interactions are displayed in Table 8.

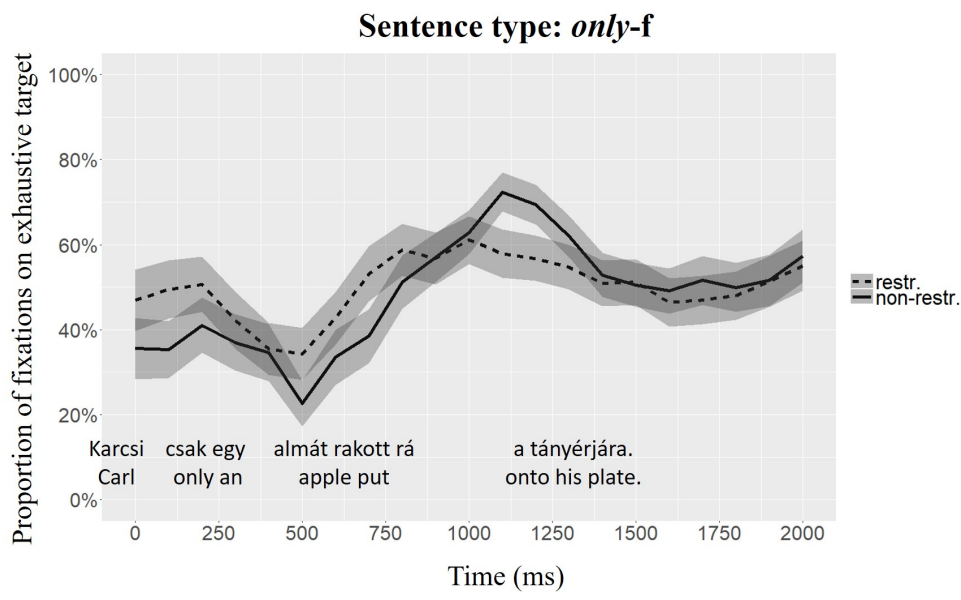

Figure 9: Mean proportion of fixations on the exhaustive target relative to the non-exhaustive competitor in the only-f-condition (ribbons: 1SE)

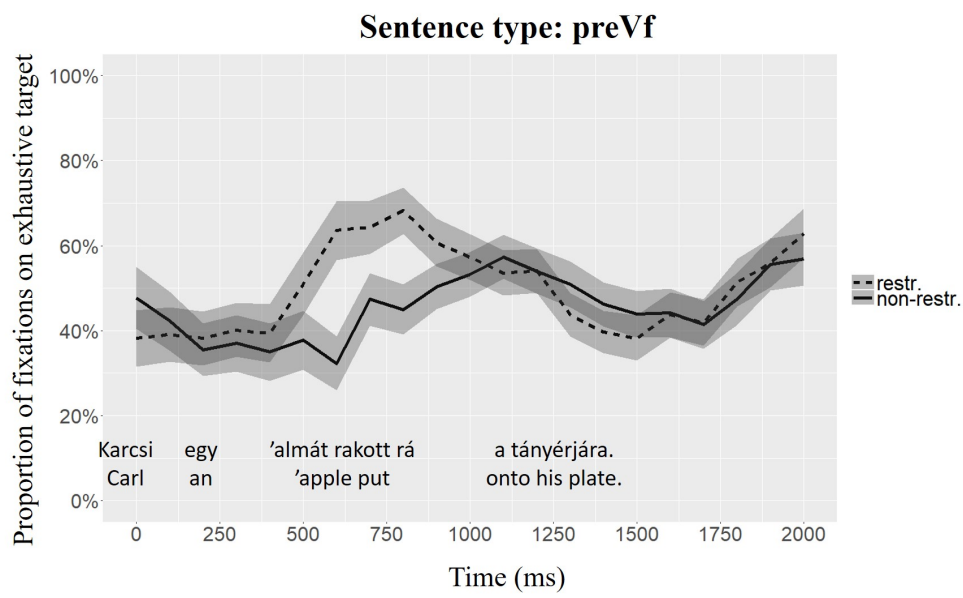

Figure 10: Mean proportion of fixations on the exhaustive target relative to the non-exhaustive competitor in the preVf-condition (ribbons: 1SE)

Looks to the Exhaustive target were overall somewhat less frequent in the preVf sentence condition than in the only sentence condition and Context also had a slight but significant main effect. In line with our predictions, however, there was a significant Context by Sentence Type interaction. Two separate models for the two Sentence Types revealed that, quite surprisingly, Context had a very weak but significant reversed effect on the 
Table 8: Regression coefficients of the model predicting eye movements

ExhTarg $\sim($ ot $1+$ ot $2+$ ot 3$) *$ Context $*$ Sentence +

$(1 \mid$ Participant $)+(1 \mid$ Item $)$, family $=$ poisson

\begin{tabular}{lrrrc}
\hline & Estimate & SE & $z$ & $p$ \\
\hline Intercept & 3.18 & 0.07 & 48.11 & $<.001$ \\
Time & 20.76 & 0.41 & 50.47 & $<.001$ \\
Time $^{\wedge} 2$ & -19.22 & 0.39 & -49.37 & $<.001$ \\
Time $^{\wedge} 3$ & -13.97 & 0.39 & -36.08 & $<.001$ \\
Context Restrictive & 0.02 & 0.00 & 4.56 & $<.001$ \\
Sentence Type PreVf & 0.01 & 0.00 & -2.92 & $=.003$ \\
Context Restrictive: & & & & \\
Sentence Type PreVf & 0.07 & 0.01 & 8.47 & $<.001$ \\
\hline
\end{tabular}

number of fixations on the Exhaustive Target in the only-f sentence condition $\left(\chi^{2}=15.03, p<.001, b=-0.02, z=-3.87, p=<.001\right)$, showing that participants were less likely to fixate on the exhaustive target in the restrictive context condition than in the non-restrictive context condition. Looking at the time course of fixations, we can see that at the beginning of a trial, restrictive context had a slight positive effect but this was reversed when the verb had been processed. This is confirmed by the regression model where the negative effect only shows up on the linear term $(b=-6.28, z=-14.77, p<.001)$ indicating that it built up gradually during the trial. This contrasts with the model for the preVf sentence type, which clearly supports our hypothesis: a restrictive context significantly increased the number of fixations on the exhaustive target relative to a non-restrictive context in the preVf sentence condition $\left(\chi^{2}=100.87, p<.001, b=0.06, z=10.04, p<.001\right)$ and this effect was strongest on the cubic term $b=4.78, z=11.91, p<.001$ ) indicating that the effect started early during the trial and persisted for a while.

\subsection{Discussion}

The results of Experiment 2 show trends that are line with our hypothesis. The rates of image choices revealed that while lexically marked focus is interpreted exhaustively independently of contextual restrictions on the availability of set alternatives, preVf is more susceptible to such contextual manipulations. The probability of exhaustive interpretation is reduced if there is no restriction on the number of potential set members which the 
focus containing sentence may refer to. In this respect, the results of Experiment 1 have been replicated. Eye-tracking data were also in line with the predictions: the proportion of fixations on the exhaustive target increased at the same rate in the case of only-f sentences in both context conditions, while a significant difference was observed in the case of preVf sentences in the predicted direction. In non-restrictive contexts, the exclusion of the non-exhaustive alternative image took considerably longer than in restrictive contexts. Again, eye-tracking data show that participants were more likely to entertain the non-exhaustive alternative in the non-restrictive context suggesting that the contextual manipulation had an effect on the mental processes associated with the exhaustive interpretation of preVf.

The effect of context on the interpretation of preVf sentences was somewhat more robust in Experiment 2 compared to Experiment 1, which is likely to be the result of the increased significance of context sentences in the successful completion of the experimental task.

The finding that the exhaustive interpretation of preVf and the related mental processes are affected by the manipulated contextual factors raises an important question regarding another word order variant: the postVf sentence type repeated in $(7 \mathrm{~b})$ for convenience.

$$
\begin{aligned}
& \text { a. Andris [egy'almát] rakott rá } \\
& \text { Andrew an apple-ACC put-3SG-PST onto }(=\mathrm{VM}) \text { the plate.his.onto } \\
& \text { 'Andrew put an 'apple onto his plate.' } \\
& \text { b. Andris rárakott [egy'almát] a tányérjára. } \\
& \text { Andrew onto-put-3SG-PST an apple-ACC the plate.his.onto } \\
& \text { 'Andrew put an apple onto his plate.' }
\end{aligned}
$$

In Experiment 3 the interpretational characteristics of postVf sentences were investigated and compared to those of preVf. In line with the findings discussed in section 1.2.3., 1.2.4. and 1.2.5., we hypothesized that the same mechanisms are at work in the computation of exhaustivity in postVf sentences as in preVf sentences. Based on this hypothesis it was predicted that both the rate of exhaustive interpretation and looking patterns will show similar context-dependent trends in the two sentence conditions.

\section{Experiment 3}

The purpose of Experiment 3 was to collect further data on the interpretational characteristics of preVf and postVf sentences. In line with the above theoretical and empirical findings we also propose that the exhaus- 
tive interpretation of postVf sentences is a pragmatic phenomenon, and as such, it is context dependent. For this reason Experiment 2 was re-run with some modifications to compare the interpretational and processing related aspects of preVf and postVf sentences.

\subsection{Participants}

36 native Hungarian adults with normal or corrected to normal vision participated in the experiment. Four participants did not reach the threshold of $75 \%$ accuracy in filler trials and were therefore excluded from further analyses leaving 32 participants ( 24 female, 8 male, mean age 22.9 years, $\mathrm{SD}=2.8)$

\subsection{Materials and procedure}

Experiment 3 compared the interpretational characteristics of preVf and postVf sentences using the trial structure of Experiment 2 with two minor modifications. An example of the linguistic stimuli is provided in Table 9.

Table 9: Example stimuli for Experiment 3

\begin{tabular}{llll}
\hline $\begin{array}{l}\text { Number } \\
\text { of sentence }\end{array}$ & $\begin{array}{l}\text { Function } \\
\text { of sentence }\end{array}$ & $\begin{array}{l}\text { Type } \\
\text { of sentence }\end{array}$ & Example \\
\hline & & restrictive & $\begin{array}{l}\text { Minden vendég vehetett a gyümölcsök közül egyet. } \\
\text { (János is vett.) 'Every guest could put ONE of the } \\
\text { fruits onto their plates. (John did so, too.) }\end{array}$ \\
\cline { 3 - 4 } 2 & context & non-restr. & $\begin{array}{l}\text { Minden vendég annyi gyümölcsöt vehetett a } \\
\text { tányérjára, amennyit csak akart. (János is vett.) } \\
\text { 'Every guest could put AS MANY fruits onto their } \\
\text { plates AS THEY WANTED. (John did so, too.)' }\end{array}$ \\
\hline \multirow{2}{*}{1} & preVf & Dániel egy 'almát vett el. 'Daniel took an 'apple.' \\
\cline { 2 - 4 } & test & OostVf elvett egy almát. 'He took an apple.' \\
\hline
\end{tabular}

One modification was the elimination of the $\mathrm{AdvP}$ from the end of the sentences. Since based on an informal survey we found that AdvPs sound somewhat odd with the type of postVf sentences we intended to investigate, we decided to present both preVf and postVf sentences without these 
elements. Furthermore, since the preVf and postVf sentences used in the experiment are word order variants of each other, the onset of the critical noun in the two sentence conditions would have been misaligned in time if they had contained exactly the same words. Therefore, the names used in preVf test sentences were replaced by personal pronouns in the postVf sentences. In order to make the context and the test sentences coherent, an additional short sentence was included in the context for the postVf sentence condition trials. This additional sentence mentioned the name of the subject of the postVf test sentence (see bracketed sentences in Table 9). In order to align the onset of the critical nouns in the two sentence-conditions, the syllables in the pre-NP region were distributed as shown in Table 10.

Table 10: Syllable distribution of the two sentence types used in Experiment 3

\begin{tabular}{lllll}
\hline Sentence type & & \multicolumn{3}{c}{ Syllables and end of sentence } \\
\hline preVf & Dá & $\mid$ ni & $\mid$ el & $\mid$ egy almát vett el. \\
postVf & Ó & $\mid$ el & $\mid$ vett & | egy almát. \\
\hline
\end{tabular}

To create a uniform and balanced trial structure throughout the experiment, half of the fillers were complemented with a short sentence containing a name in the context part of the trial. Correspondingly, names in the second sentence of these trials were replaced with a personal pronoun. All other aspects of the experiment remained constant.

The linguistic stimuli of Experiment 3 were recorded in a sound treated room with an external sound card and an omnidirectional microphone (digitized at $44.1 \mathrm{kHz}$ sampling rate and at 16 bit resolution) in the production of an adult Hungarian female. As in Experiments 1 and 2 , we asked our speaker to produce the linguistic material as naturally as possible. As an illustration of the f0, contours corresponding to the relevant prosodic aspects of the test sentences, a prototypical example for both sentence types are shown in Figure 11 and 12.

The flat prosody of the post-verbal elements observed in Figure 12 deserves a mention especially in light of Surányi (2011), who claims that postVf is prosodically prominent. Based on this claim, one can assume that the use of the recorded linguistic stimuli would render our results invalid, since the critical sentences did not correspond entirely to what is descriptionally stated about their type. In our view, however, this is not the case for a number of reasons. 


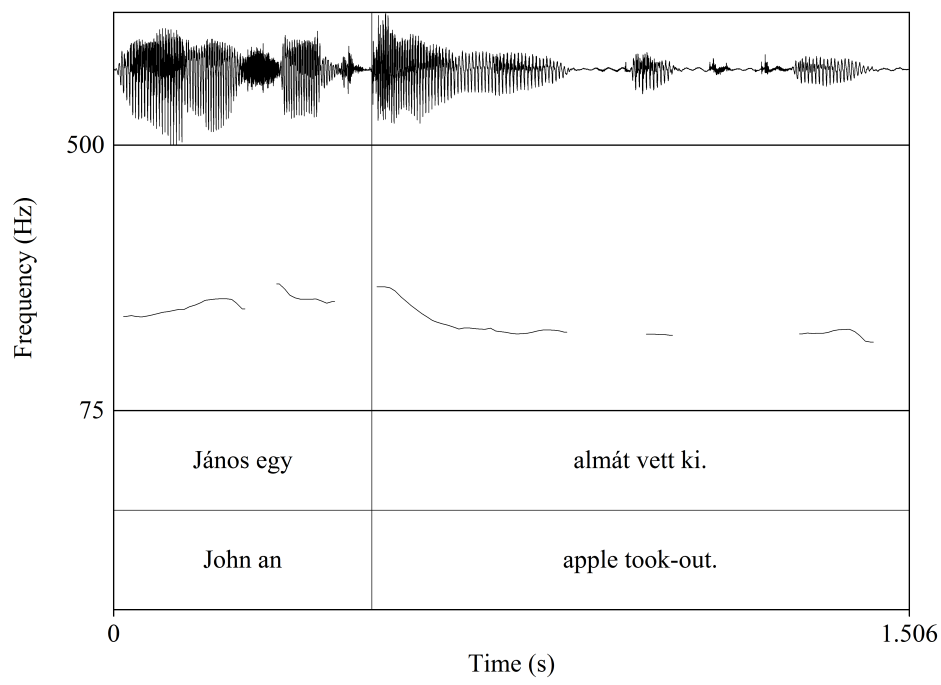

Figure 11: The f0 contour of a prototypical preVf sentence used in Experiment 3

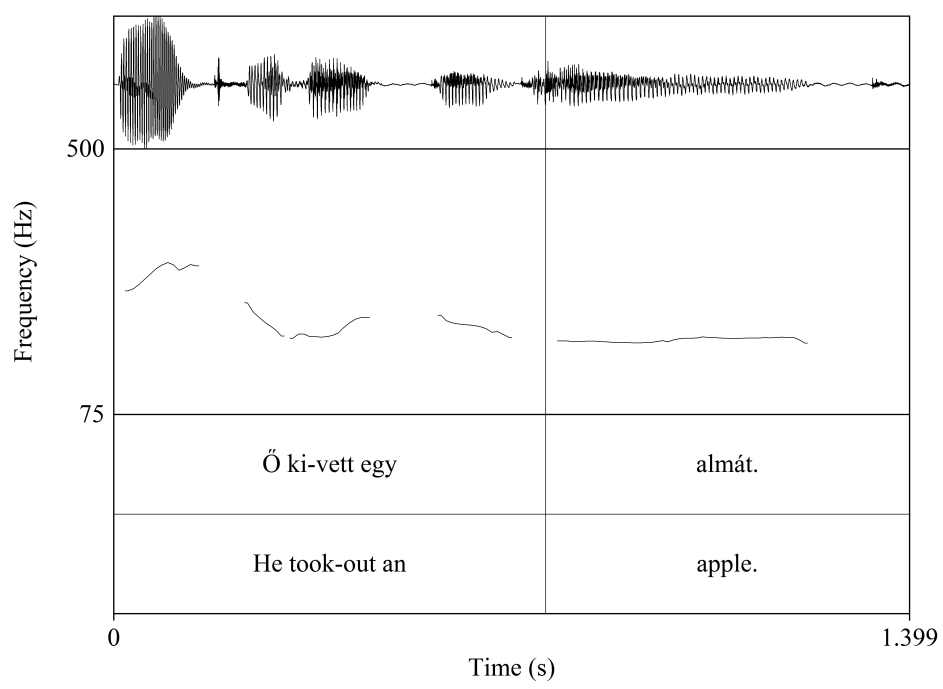

Figure 12: The fo contour of a prototypical postVf sentence used in Experiment 3

First of all, Surányi (2011) is a theoretical work, and as such, although an important contribution to the subject matter at hand, it relies on the intuition of the author and not on precise measurement carried out on phonetic data. To illustrate the point about the intuition regarding the prosody of focus, let us consider a production and perception study car- 
ried out by Mády (2015). The author elicited different types of (pre-verbal) foci (narrow, broad and contrastive) by read out question-answer pairs and measured the prosodic features of the focused elements. The measurements revealed that - contrary to intuition - there was no reliable difference in the prosodic realizations of the different types of foci. In the perception study participants were presented prosodically manipulated focus sentences in different contexts. The task was to rate the naturalness of the focus containing sentences in the different contexts. Results revealed that a higher f0 increased the ratings only in the narrow focus condition. Furthermore, results of the two experiments also revealed high individual variation both in the production and in the perception of the prosodic characteristics of focus. Therefore, Mády $(2015,948)$ concludes that there is "weak evidence for the relevance of tonal cues for focus marking in Hungarian", and also that "prosodic focus marking in Hungarian is optional and pragmatic rather than grammatical and syntax-related". Although Mády (2015) investigated the prosodic aspects of pre-verbal element, these results clearly indicate that intuition regarding (focus) prosody are not entirely reliable and have to be taken with caution.

Second, Pintér (2018) mentions that sentences with neutral word order and prosody can also have an exhaustive interpretation; a meaning component frequently associated with focus. Taking this claim and Mády's (2015) conclusion into consideration it becomes apparent that the concept of postVf is descriptionally vague, which is attributable, at least in our minds, to the lack of sufficient experimental data on the phenomenon at hand. For this reason we resort to a functional definition provided by É. Kiss (1998) according to which postVf (or "information focus" in her terminology) conveys non-presupposed information. ${ }^{13}$ We consider É. Kiss's (1998) definition the most crucial element of our argument.

This leads us to the third point: we asked our speaker to produce the context and critical sentences in a natural way. Since the contexts were created in a way that the post-verbal element in the critical sentences carried non-presupposed information (i.e., strictly corresponded to the above mentioned definition), we have confidence that according to our speaker's intention, postVf sentences were produced. Also, the informal debriefing after the experiment revealed that participants considered the linguistic stimuli natural and did not detect any peculiarity nor prosodically, nor otherwise.

13 Note, however, that É. Kiss (1998) also makes reference to a "pitch accent" carried by the focused element. However, this is rather a descriptional and not a definitional remark. 
Thus, for the above mentioned set of reasons we concluded that the recorded linguistic material is suitable for the investigation of the interpretational characteristics of postVf sentences.

\subsection{Results}

\subsubsection{Rate of exhaustive responses}

The results clearly supported our predictions for both image choice rates and eye-gaze patterns Figure 13.

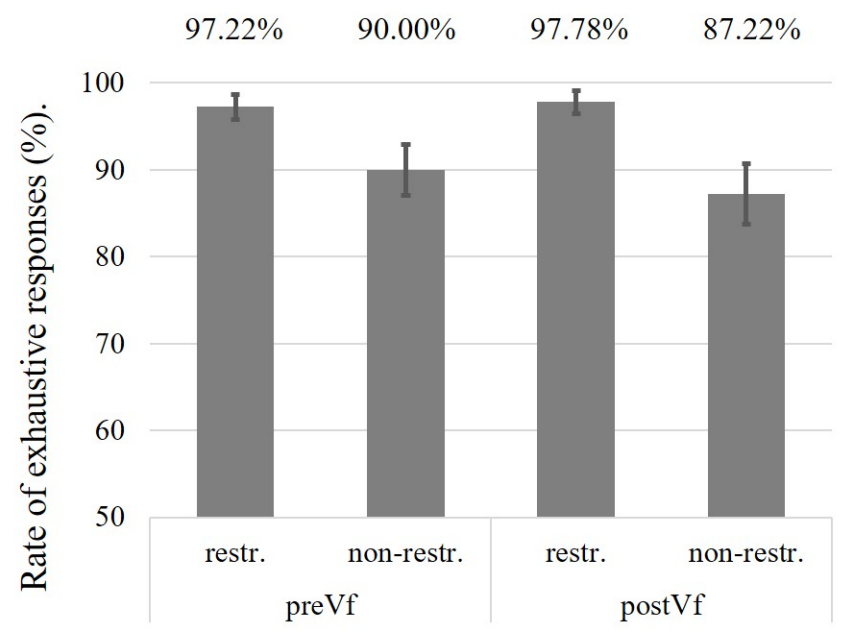

Figure 13: Rate of exhaustive response type in the four conditions

For the statistical analysis of the response data, a series of binomial Logistic Mixed Effects Models were fitted with Participant and Item as random factors and Context and Sentence Type as fixed factors, as for Experiment 1 . The outcome variable was the participants' response, which could be exhaustive (0) or non-exhaustive (1). Model building started with a full random structure and, if the model failed to converge, the structure was gradually simplified. This procedure resulted in models with random intercepts for Participant and Item. The fixed effects structure was built bottom up starting with an intercept-only model, to which the two fixed effects and their interaction were added one by one. This time, as predicted, the addition of Context significantly improved model fit $\left(\chi^{2}=20.02, p<.001\right)$ but the addition of Sentence Type $\left(\chi^{2}=1.13, p=0.29\right)$ or the interaction 
term $\left.\chi^{2}=0.09, p=0.76\right)$ did not. To obtain coefficients for the simple effect of Context in the two Sentence Types, two separate models were built as explained above. The results are shown in Table 11: the coefficients indicate the effect of a Restrictive Context compared to a Non-Restrictive context on the likelihood of giving a Non-Exhaustive response. As we can see, a restrictive context reduced the likelihood of giving a non-exhaustive response in both sentence conditions.

Table 11: Regression coefficients of the effect of a Restrictive Context on a NonExhaustive response

Response $\sim$ Context $+(1 \mid$ Participant $)+(1 \mid$ Item $)$, family $=$ binomial

\begin{tabular}{lcccl}
\hline & Estimate & SE & $z$ & $p$ \\
\hline PostVf Sentence Type & -2.29 & 0.90 & -2.54 & .01 \\
PreVf Sentence Type & -1.90 & 0.68 & -2.77 & .005 \\
\hline
\end{tabular}

\subsubsection{Eye-tracking data}

The data were analyzed using mixed-effects logistic regression models with Participant and Item as random effects (Barr, 2008; Jaeger, 2008). The models used a Poisson distribution and predicted the number of fixations per $100 \mathrm{~ms}$ on the Exhaustive Target image over Time from the offset of the subject NP in the test sentence to the end of the test sentence shifted by $200 \mathrm{~ms}$ to allow for the planning and execution of eye movements (Allopenna et al. 1998). The models were built starting with an intercept-only model and gradually adding the fixed effects and their interactions. The models were compared using the likelihood ratio test and complexity was increased until the addition of a new term no longer improved model fit. In the final, best-fitting model, Context and Sentence Type and their interaction were included as fixed effects on a third-order orthogonal polynomial capturing Time. A third-order polynomial was selected because it was a significantly better fit than either a linear model or a second-order polynomial as described by Mirman (2014). A full random effects model with random slopes for the various conditions failed to converge and was therefore removed from the analyses leaving a random intercept model for Participant and Item.

Where interaction terms were significant, separate mixed models were built to assess the simple slopes of the fixed factors while keeping all other model parameters constant. 
Figures 14 and 15 show the mean frequency of fixations on the Exhaustive Target Image as a percentage of fixations on the target plus the competitor every 100 milliseconds in the Restrictive and Non-Restrictive Context conditions for postVf sentences and preVf sentences. Selected final model parameter estimates with main effects and overall interactions are displayed in Table 12.

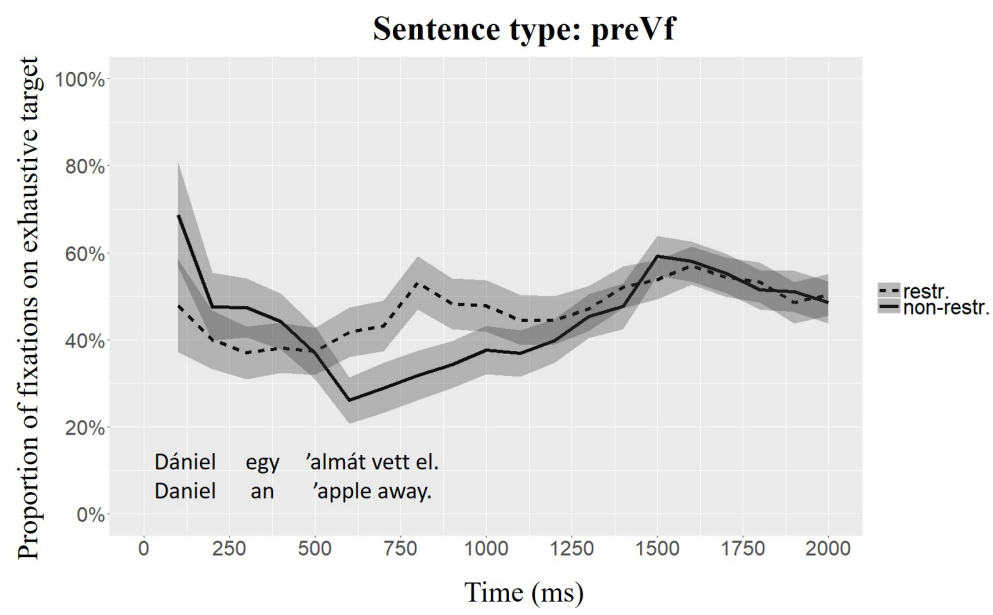

Figure 14: The mean proportion of fixations to exhaustive target relative to the non-exhaustive competitor in the preVf condition (ribbons: 1SE)

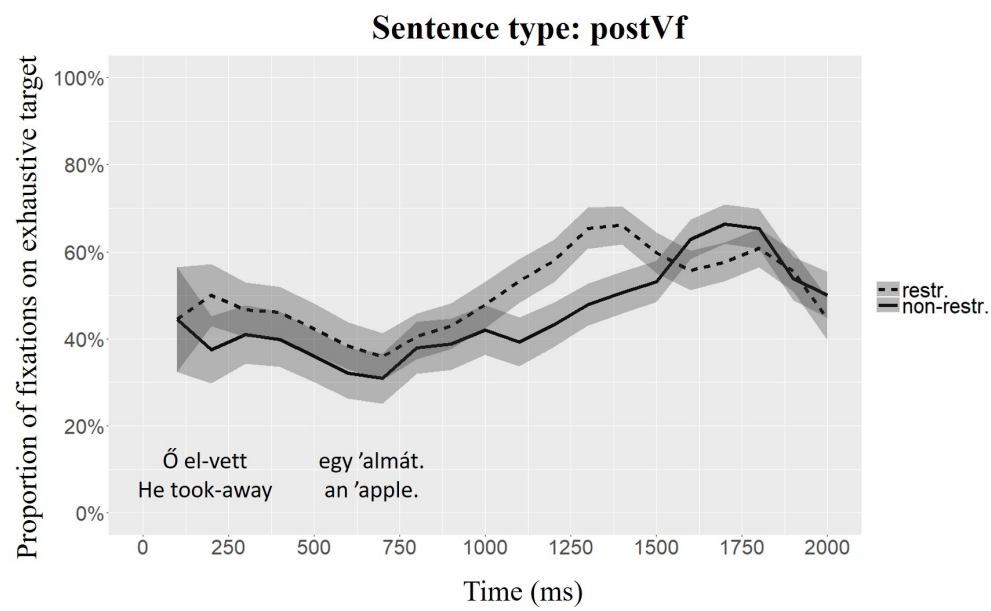

Figure 15: The mean proportion of fixations to exhaustive target relative to the non-exhaustive competitor in the postVf condition (ribbons: 1SE) 
Table 12: Regression coefficients of the model predicting eye movements

\begin{tabular}{|c|c|c|c|c|}
\hline & Estimate & $\mathrm{SE}$ & $z$ & $p$ \\
\hline Intercept & 3.01 & 0.07 & 42.56 & $<.001$ \\
\hline Time & 32.49 & 0.39 & 82.52 & $<.001$ \\
\hline Time $^{\wedge} 2$ & 6.93 & 0.43 & 15.59 & $<.001$ \\
\hline Time $^{\wedge} 3$ & -33.38 & 0.45 & -74.57 & $<.001$ \\
\hline Context Restrictive & 0.06 & 0.00 & 17.04 & $<.001$ \\
\hline Sentence Type PreVf & -0.06 & 0.00 & -16.20 & $<.001$ \\
\hline \multicolumn{5}{|l|}{ Context Restrictive: } \\
\hline Sentence Type PreVf & -0.08 & 0.01 & -10.77 & $<.001$ \\
\hline
\end{tabular}

Looks to the Exhaustive target were somewhat less frequent in the preVf sentence condition than in the postVf sentence condition. As predicted, Context had a slight but significant main effect with more fixations on the Exhaustive target in the restrictive condition than in the non-restrictive condition irrespective of Sentence Type. There was also a significant Context by Sentence Type interaction, however. Two separate models for the two Sentence Types revealed that Context had a significant effect on the number of fixations on the Exhaustive Target in the post $\mathrm{Vf}$ sentence condition $\left(\chi^{2}=302.12, p<.001, b=0.09, z=17.36, p<.001\right)$, showing that participants were overall more likely to fixate on the exhaustive target in the restrictive context condition than in the non-restrictive context condition. The effect was strongest on the cubic term $(b=8.76, z=18.28, p<$ .001). The model for the preVf sentence type gives similar results: a restrictive context significantly increased the number of fixations on the exhaustive target relative to a non-restrictive context in the preVf sentence condition $\left(\chi^{2}=12.72, p<.001, b=0.02, z=3.57, p<.001\right)$. The effect is once again strongest on the cubic term $(b=5.72, z=13.79, p<.001)$. In conclusion, restrictive context increases the frequency of fixations on the exhaustive target for both postVf and preVf sentences and the significant interaction seems to be due to the slightly delayed effect in the postVf sentence condition. This is not surprising since in the postVf sentence condition, listeners need to wait for the end of the sentence before they can be certain that no second object noun is coming. 


\subsection{Discussion}

The results of the preVf-condition in Experiment 2 have been replicated in Experiment 3. Furthermore, the results of Experiment 3 in the postVf condition are in line with earlier theoretical and experimental findings regarding the interpretation of postVf sentences.

\section{General discussion}

The current study examined predictions based on the Constraint-based model of implicature generation with regards to the exhaustive interpretation of two Hungarian sentence types: preVf and postVf sentences. According to the Constraint based model, both the rate of pragmatically enriched interpretation and the mental processes associated with it are affected by contextual factors: the integration of contextual information and the generation of expectations are the relevant mechanisms behind the process of interpretation. Since the literature suggests that exhaustivity arises as a (potentially scalar-type) implicature in the sentence types at hand, we looked at this meaning component in two types of context. One context type introduced a restriction on the number of referents to which the focused element of the target sentence could hold, while the other context type did not introduce such a restriction. In addition to preVf and postVf sentence structures, we used lexically marked focus (only-f), which served as a baseline. Due to the fact that only-f sentences are lexically marked for exhaustivity, their interpretation is semantically determined and they are not predicted to be susceptible to contextual manipulation. In line with this, we predicted that only-f sentences will be reliably exhaustive in all context conditions. By contrast, it was predicted that the introduced contextual factor will have an effect on the rate of exhaustive interpretation for both preVf and postVf sentences. Regarding eye-tracking data, it was predicted that the proportion of looks to the exhaustive target will be uniform in the two context conditions in the case of only-f sentences, while looks will diverge across context conditions in the case of preVf and postVf sentences. In both of the latter two sentence types, it was predicted that eye-gaze data will reflect more competition between the exhaustive target and the non-exhaustive alternative in non-restrictive contexts than in restrictive contexts.

Our hypotheses were corroborated by the results: while the rate of exhaustive interpretation and the associated mental processes were not 
affected by contextual factors in the case of only-f sentences, effects in the predicted direction were observed both in preVf and in postVf sentences.

The Constraint-based model further predicts that as the pragmatically enriched meaning is calculated immediately if context supports it, the effect of context should appear early during processing. Once again, our results are in line with this prediction: a restrictive context increased the likelihood of fixations on the exhaustive target as soon as the critical object NP was heard.

In the following paragraphs the response patterns and eye-tracking data will be briefly discussed.

\subsection{High rates of exhaustive interpretation - potential explanations}

The high proportion of exhaustive responses relative to earlier experimental results in both preVf and postVf sentences deserves a mention. The high rates of exhaustive reading may be accounted for by Káldi et al's (in prep) results. The authors use Kenesei's (2006) account of focus and sets as their premise: Kenesei (2006) proposes that in the case of a preVf sentence a complementary set is always created regardless of whether this set is explicit or implicit in the given context. The preVf sentence will operate on one or more elements of this set (for more detail on identification by exclusion see section 1.2.2). Based on this premise, Káldi et al. (in press) using a guided production paradigm examined the contexts that facilitate the use of preVf word order sentences. The experiment presented different contexts followed by word salads. The experimental task was to put the words of the word salad in order in a way that the resulting sentence fits the preceding context. The authors have shown that if the context included either an implicit or an explicit set (through category name or through a list), participants produced preVf sentences at a significantly higher rate than when the context did not contain a set at all. These results support Kenesei's (2006) account, and it seems highly likely that the sets used in the present experiments (explicit in Experiment 1, and implicit in Experiments 2 and 3 ) facilitated the exhaustive interpretation of preVf. Since in Experiment 3 it was shown that the exhaustive interpretation of preVf and postVf sentences are tied to very similar pragmatic processes, it also seems plausible that the relatively high rate of exhaustive responses in the postVf sentence conditions are also a result of the presence of sets in the context. These conjectures may serve as a basis for future research.

The results of Gerőcs et al. (2014) also offer a very similar explanation for the relatively high proportion of exhaustive responses. The authors 
used two experiments to investigate the exhaustive interpretation of preVf, only-f, postVf and cleft sentences (for further details see section 1.2.3). In the first experiment the authors used a question corresponding to an image which depicted a set of objects. As this setup introduced an implicit set through the question and the presented image, the rates of exhaustive interpretation of both preVf and postVf sentences were high $(72 \%$ and $63 \%$ respectively). The second experiment, however, used a sentence - picture matching task, and included neither a question, nor an implicit or explicit set. As expected, the rates of exhaustive image choices were low (35\% for preVf and $7 \%$ for postVf) relative to the first experiment and all experiments in the current study.

Another potential explanation for the high rate of exhaustive interpretation of preVf and postVf sentences may be related to domains as discussed by Stanley and Szabó (2000). According to the authors, certain quantifiers that are associated with scalar implicature in the literature actually operate in contextually defined domains. Based on this, it seems reasonable to say that in the case of out-of-context sentences, like the ones that had been used in earlier experiments on preVf interpretation, the domains were not as strictly defined as in the case of the experiments reported in the current paper, and interpretation rates were closer to chance level as a consequence.

It is important to note, however, that the results reported here are not directly comparable with those in Káldi et al. (2017), an antecedent to the current paper. While the test sentences used in Káldi et al. (2017) contained NPs with definite articles, the present experiment used indefinite articles. To the best of our knowledge, there is no experimental data on the potential effects of article type on the exhaustive interpretation of preVf and postVf sentences.

\subsection{Modular versus Constraint-based models of scalar implicature generation}

The results are informative with regard to models of sentence processing, or more specifically, to models of scalar implicature generation. In section 1.1. we provided a brief outline of the two opposing views dominant in the literature: the Modular and Constraint-based models. Advocates of the former claim that implicature derivation takes place in two steps: first the semantic interpretation of the given structure is carried out (at least to some degree) and next, the pragmatically enriched interpretation is computed based on the semantic, truth conditional analysis and other, contextual and extra-linguistic factors. Processing-wise the model predicts 
that there should be a delay for scalar terms relative to expressions whose interpretation can be calculated purely at the level of semantics. For eyetracking data this would mean a delay of looks to a target which corresponds to the pragmatically enriched interpretation of the given scalar term. A Constraint-based model does not predict such a delay, since it claims that contextual factors are taken into consideration throughout the process of interpretation, and pragmatically enriched meaning is calculated immediately if context supports it. The results of the current experiment support the Constraint-based model: when participants were encouraged to pay particular attention to the contexts (Experiment 2 and 3), the the effect of context appeared earlier, immediately after the onset of critical noun. These results clearly indicate that the process of interpretation is mediated by contextually given information online. Put it differently, mental processes of linguistic interpretation are constrained by relevant contextual information.

\subsection{Status of exhaustivity in preVf and postVf}

The eye-tracking data gathered in the present experiments provide further evidence for the view that the exhaustive interpretation associated with preVf and postVf emerges as a scalar-type implicature. While the mental interpretational processes associated with only-f sentences were not affected by the contextual manipulation, in the case of preVf it has been demonstrated that in non-restrictive contexts participants entertained the non-exhaustive alternative to a greater extent than in the case of restrictive contexts even though they eventually gave an exhaustive response. A similar pattern was found in postVf sentences. We conclude that the slower convergence on the exhaustive targets in the non-restrictive conditions is indicative of processes that are associated with pragmatic inferences. In line with the theoretical considerations in section 1.2, the exhaustive interpretation of preVf and postVf sentences is best categorized as a scalar-type pragmatic implicature.

\subsection{Further considerations}

The observed differences between the results of Experiment 1 and 2 are valuable from a methodological point of view, as well.

The most important difference between the eye-gaze patterns observed in the two experiments is that while the expected divergence was limited to 
the AdvP region in Experiment 1, this divergence occurred during the NP region (immediately after the onset of the critical noun) and until the end of the verb in Experiment 2. Earlier (see sections 2.5., 3.4) it was already pointed out that one crucial factor contributing to this difference may have been the type of fillers used. While in Experiment 1 important aspects of the experimental setup were not taken into consideration in the fillers, these limitations were remedied in Experiment 2. A careful definition of features in fillers resulted in a more strictly controlled experiment. Since it has been shown that fillers can significantly affect data patterns obtained in an experiment, the authors of the present paper would like to highlight the importance of reporting the structure of the linguistic material of not only critical trials in publications of psycholinguistic experiments but also that of filler trials. This consideration is especially important from the point of view of replicability.

In conclusion, the results reported in the present paper support the Constraint-based model of implicature generation and corroborate the hypothesis that the exhaustive interpretation associated with the Hungarian pre-verbal and post-verbal foci are tied to pragmatic implicatures.

\section{Acknowledgements}

The authors are grateful to the following colleagues: Csilla Horváth, Ágnes Lukács, Péter Pajkossy, Andrea Deme, Katalin É. Kiss and Balázs Surányi.

\section{References}

Allopenna, D., Paul, S. Magnuson, James and K. Tanenhaus, Michael. 1998. Tracking the time course of spoken word recognition using eye movements: Evidence for continuous mapping models. Journal of Memory \& Language 38. 419-439.

Babarczy, Anna and Andrea Balázs. 2016. A kognitív kontroll és a preverbális fókusz értelmezése [Cognitive control and the interpretation of the preverbal focus]. In Kas (2016, 151-163).

Barr, Dale J. 2008. Analyzing 'visual world' eyetracking data using multilevel logistic regression. Journal of Memory \& Language 59. 457-474.

Bates, Douglas, Martin Maechler, Ben Bolker and Steve Walker. 2015. Fitting linear mixedeffects models using lme4. Journal of Statistical Software 67. 1-48.

Bergen, Leon and Daniel J. Grodner. 2012. Speaker knowledge influences the comprehension of pragmatic inferences. Journal of Experimental Psychology: Learning, Memory, and Cognition 38. 1450-1460.

Boersma, Paul and David Weenink. 2005. Praat: Doing phonetics by computer. (Version 6.0.35). (Computer program). Retrieved from http://www.praat.org/. 
Bott, Lewis and Ira A. Noveck. 2004. Some utterances are underinformative: The onset and time course of scalar inferences. Journal of Memory and Language 51. 437-457.

Breheny, Richard, J. Ferguson, Heather and N. Katsos. 2013. Investigating the time course of accessing conversational implicatures during incremental sentence interpretation. Language and Cognitive Processes 28. 443-467.

De Neys, Wim and Walter Schaeken. 2007. When people are more logical under cognitive load: Dual task impact on scalar implicature. Experimental Psychology 54. 128-133.

Degen, Judith and K. Tanenhaus, Michael. 2011. Making inferences: The case of scalar implicature processing. Proceedings of the 33rd annual conference of Cognitive Science Society 33. 3299-3304.

Degen, Judith and Michael K. Tanenhaus. 2015. Processing scalar implicature: A constraintbased approach. Cognitive Science 39. 667-710.

É. Kiss, Katalin (ed.). 1995. Discourse configurational languages. Oxford: Oxford University Press.

É. Kiss, Katalin. 1998. Identificational focus versus information focus. Language 74. 245273.

É. Kiss, Katalin. 2002. The syntax of Hungarian. Cambridge: Cambridge University Press.

É. Kiss, Katalin. 2006. Érvek és ellenérvek a fókusz [+kimerítô] jegyével kapcsolatban [Arguments and counterarguments regarding the [+exhaustive] feature of the focus]. In L. Kálmán (ed.) KB 120: A titkos kötet. Nyelvészeti tanulmányok Bánréti Zoltán és Komlósy András tiszteletére [KB 120: The secret volume. Studies in linguistics in honour of Zoltán Bánréti and András Komlósy]. Budapest: MTA Nyelvtudományi Intézet \& Tinta Könyvkiadó. 37-48.

É. Kiss, Katalin. 2008. Topic and focus: Two structural positions associated with logical functions in the left periphery of the Hungarian sentence. Acta Linguistica Hungarica 55. 287-296.

Edmonds, Joseph and Markéta Janebová (eds.). 2017. Language and linguistic structure. Proceedings of the Olomouc Linguistics Colloquium 2016 (Olomouc Modern Language Series vol. 5). Olomouc: Palacký University.

Farkas, Donka. 1986. The syntactic position of focus in Hungarian. Natural Language \& Linguistic Theory 4. 77-96.

Foppolo, Francesca and Maria Teresa Guasti. 2012. Scalar implicatures in child language: Give children a chance. Language Learning and Development 8. 365-394.

Foppolo, Francesca and Marco Marelli. 2017. No delay for some inferences. Journal of Semantics 34. 659-681.

Gazdar, Gerald. 1979. Pragmatics: Implicature, presupposition, and logical form. New York: Academic Press.

Genzel, Susanne, Shinichiro Ishihara and Balázs Surányi. 2015. The prosodic expression of focus, contrast and givenness: A production study of Hungarian. Lingua 165. 183-204.

Gerôcs, Mátyás, Anna Babarczy and Balázs Surányi. 2014. Exhaustivity in focus: Experimental evidence from Hungarian. In J. Emonds and M. Janebová (eds.) Language use and linguistic structure. Olomouc: Palacký University. 181-194.

Geurts, Barts and Paula Rubio-Fernández. 2015. Pragmatics and processing. Ratio 28. 446-469.

Grice, H. Paul. 1957. Meaning. Philosophical Review 67. 377-388. 
Grice, H. Paul. 1975. Logic and conversation. In P. Cole and J. L. Morgan (eds.) Syntax and semantics, vol. 3: Speech acts. New York: Academic Press. 41-58.

Grice, H. Paul. 1989. Studies in the way of words. Cambridge, MA: Harvard University Press.

Grodner, Daniel J., Kathleen M. Klein, Natalie M. Carbary and K. Tanenhaus, Michael. 2010. "Some", and possibly all, scalar inferences are not delayed: Evidence for immediate pragmatic enrichment. Cognition 116. 42-55.

Horn, Larry. 1972. On the semantic properties of logical operators in English. Doctoral dissertation. UCLA.

Horvath, Julia. 2010. "Discourse features", syntactic displacement and the status of contrast. Lingua 120. 1346-1369.

Huang, Yi Ting and Jesse Snedeker. 2009. Online interpretation of scalar quantifiers: Insight into the semantics-pragmatics interface. Cognitive Psychology 58. 376-415.

Jaeger, Florian. 2008. Categorical data analysis: Away from ANOVAs (transformation or not) and towards Logit Mixed Models. Journal of Memory and Language 59. 434-446.

Káldi, Tamás. 2016. A magyar pre-verbális fókusz interpretációjának tulajdonságai egészséges és Broca-afáziás személyeknél [The interpretational characteristics of the Hungarian pre-verbal focus in Broca-aphasic patients]. In Zs. Gécseg (ed.) LingDok 14. Nyelvész-doktoranduszok dolgozatai [Papers by doctoral students of linguistics]. Szeged: Szegedi Tudományegyetem Nyelvtudományi Doktori Iskola. 105-124.

Káldi, Tamás and Anna Babarczy. 2016. A magyar fókusz és a skaláris implikatúrák: egy szemmozgás-követéses kutatás eredményei [The Hungarian focus and scalar implicature: The results of an eye-tracking experiment]. In Kas (2016, 333-346).

Káldi, Tamás, Anna Babarczy and Ágnes Bende-Farkas. 2017. Hungarian focus: Presuppositional content and exhaustivity revisited. In Edmonds \& Janebová (2017, 245-262).

Káldi, Tamás, Levente Madarász, and Anna Babarczy. in press. Contextual triggers of the pre-verbal focus word order - A guided production study. In Approaches to Hungarian. Amsterdam \& Philadelphia: John Benjamins.

Kas, Bence (ed.). 2016. "Szavad ne feledd!" - Tanulmányok Bánréti Zoltán tiszteletére [Papers in honour of Zoltán Bánréti ]. Budapest: MTA Nyelvtudományi Intézet.

Kas, Bence and Ágnes Lukács. 2013. Focus sensitivity in Hungarian adults and children. Acta Linguistica Hungarica 60. 217-245.

Katsos, Napoleon and Dorothy V. M. Bishop. 2011. Pragmatic tolerance: Implications for the acquisition of informativeness and implicature. Cognition 20. 67-81.

Kenesei, István. 2005. Hungarian in focus (Review article). Journal of Linguistics 41. 409-35.

Kenesei, István. 2006. Focus as identification. In V. Molnár and S. Winkler (eds.) The architecture of focus (Studies in Generative Syntax 82). Berlin \& New York: Mouton de Gruyter. 137-168.

Kenesei, István. 2009. Quantifiers, negation, and focus on the left periphery in Hungarian. Lingua 119. 564-591.

Kornai, András and László Kálmán. 1988. Hungarian sentence intonation. In H. van der Hulst and N. Smith (eds.) Autosegmental studies on pitch accent. Dotrecht: Foris. 183-195.

Levinson, Stephen C. 2000. Presumptive meanings: The theory of generalized conversational implicature. Cambridge, MA: MIT Press. 
Mády, Katalin. 2015. Prosodic (non-)realisation of broad, narrow and contrastive focus in Hungarian: A production and perception study. In Interspeech 2015. Proceedings of the 16th Annual Conference of the International Speech Communication Association. Dresden: ISCA. 948-952.

Marr, David. 1982. Vision: A computational investigation into the human representation and processing of visual information. San Francisco: W. H. Freeman.

Mirman, Daniel. 2017. Growth curve analysis and visualization using R. Boca Raton, FL: CRC Press.

Noveck, Ira A. 2001. When children are more logical than adults: Experimental investigations of scalar implicature. Cognition 78. 165-188.

Noveck, Ira A. and Andres Posada. 2003. Characterizing the time course of an implicature: An evoked potentials study. Brain and Language 85. 203-210.

Onea, Edgar and David Beaver. 2011. Hungarian focus is not exhausted. In S. Ito and E. Cormany (eds.) Semantics and Linguistic Theory (SALT) 19. Ithaca, NY: CLC Publications. 342-359.

Pintér, Lilla. 2018. The acquisition of asserted, presupposed, and pragmatically implied exhaustivity in Hungarian. Acta Linguistica Academica 65. 353-383.

R Development Core Team. 2017. R: A language and environment for statistical computing. Vienna: Foundation for Statistical Computing. http://www.R-project.org

Skopeteas, Stavros and Gisbert Fanselow. 2011. Focus and the exclusion of alternatives: On the interaction of syntactic structure with pragmatic inference. Lingua 121. 1693-1706.

Sperber, Dan and Deirdre Wilson. 1995. Relevance: Communication and cognition. Second edition. Cambridge, MA \& Oxford: Blackwell.

Stanley, Jason and Zoltán Gendler Szabó. 2000. On quantifier domain restriction. Mind and Language 15. 219-261.

Surányi, Balázs. 2011. A szintaktikailag jelöletlen fókusz pragmatikája [On the pragmatics of syntactically unmarked focus]. Általános Nyelvészeti Tanulmányok 23. 281-313.

Szabolcsi, Anna. 1980. Az aktuális mondattagolás szemantikájához [On the semantics of actual sentence segmentation]. Nyelvtudományi Közlemények 82. 59-82.

Szabolcsi, Anna. 1981. Compositionality in focus. Folia Linguistica 15. 141-161.

Szendrôi, Kriszta. 2003. A stress-based approach to the syntax of Hungarian focus. The Linguistic Review 20. 37-78.

Tomlinson, John M., Todd M. Bailey and Lewis Bott. 2013. Possibly all of that and then some: Scalar implicatures are understood in two steps. Journal of Memory \& Language 69. 18-35.

Tóth, Péter and Enikô Csatár. 2017. Preverbal focus and syntactically unmarked focus: A comparison. In Edmonds \& Janebová (2017, 227-244).

Wedgwood, Daniel. 2005. Shifting the focus. From static structures to the dynamics of interpretation. Amsterdam: Elsevier.

Wedgwood, Daniel, Gergely Pethő and Ronnie Cann. 2006. Hungarian 'focus position' and English it-clefts: Semantic underspecification of 'focus' readings. Ms. University of Edinburgh.

Wickham, Hadley. 2009. ggplot2: Elegant graphics for data analysis. New York: Springer. 
